\title{
Littorally adaptive? Testing the link between habitat, morphology, and reproduction in the intertidal sculpin subfamily Oligocottinae (Pisces: Cottoidea)
}

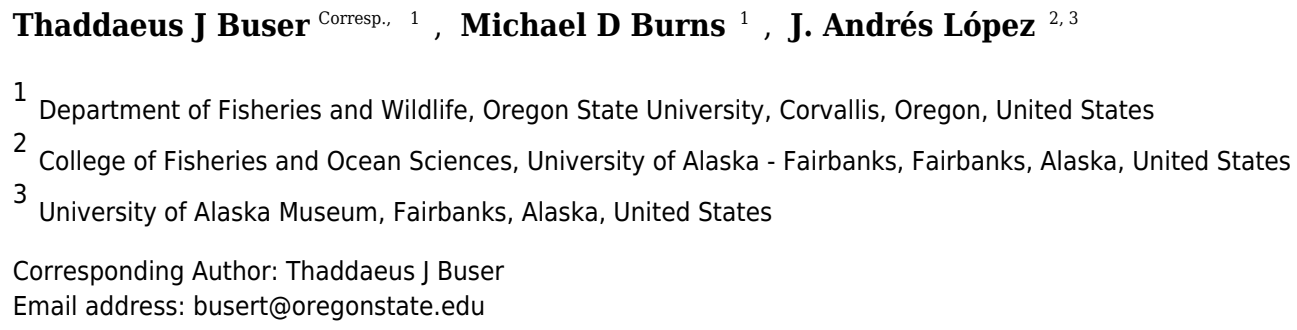

While intertidal habitats are often productive, species-rich environments, they are also harsh and highly dynamic. Organisms that live in these habitats must possess morphological and physiological adaptations that enable them to do so. Intertidal fishes are generally small, often lack scales, and the diverse families represented in intertidal habitats often show convergence into a few general body shapes. However, few studies have quantified the relationship between phenotypes and intertidal living. Likewise, the diversity of reproductive traits and parental care in intertidal fishes has yet to be compared quantitatively with habitat. We examine the relationship of these characters in the sculpin subfamily Oligocottinae using a phylogenetic hypothesis, geometric morphometrics, and phylogenetic comparative methods to provide the first formal test of associations between fish phenotypes and reproductive characters with intertidal habitats. We show that the ability to live in intertidal habitats, particularly in tide pools, is likely a primitive state for Oligocottinae, with a single species that has secondarily come to occupy only subtidal habitats. Contrary to previous hypotheses, maximum size and presence of scales do not show a statistically significant correlation with depth. However, the maximum size for all species is generally small $(250 \mathrm{~mm}$ or less) and all show a reduction in scales, as would be expected for an intertidal group. Also contrary to previous hypotheses, we show that copulation and associated characters are the ancestral condition in Oligocottinae, with copulation most likely being lost in a single lineage within the genus Artedius. Lastly, we show that body shape appears to be constrained among species with broader depth ranges, but lineages that occupy only a narrow range of intertidal habitats display novel body shapes, and this may be associated with habitat partitioning, particularly as it relates to the degree of wave exposure. 
1 Littorally adaptive? Testing the link between habitat, morphology, and reproduction in the 2 intertidal sculpin subfamily Oligocottinae (Pisces: Cottoidea)

3

4 Thaddaeus J. Buser ${ }^{1}$, Michael D. Burns ${ }^{1}$, and J. Andrés López ${ }^{2,3}$

5

$6{ }^{1}$ Department of Fisheries and Wildlife, Oregon State University, Corvallis, Oregon, USA

$7{ }^{2}$ College of Fisheries and Ocean Sciences, University of Alaska Fairbanks, Fairbanks, Alaska, 8 USA

9 3University of Alaska Museum, Fairbanks, Alaska, USA 10

11

12 Corresponding author:

13 Thaddaeus Buser ${ }^{1}$

14

15

16

Email address: busert@oregonstate.edu 


\section{Abstract}

18 While intertidal habitats are often productive, species-rich environments, they are also harsh and highly dynamic. Organisms that live in these habitats must possess morphological and physiological adaptations that enable them to do so. Intertidal fishes are generally small, often lack scales, and the diverse families represented in intertidal habitats often show convergence into a few general body shapes. However, few studies have quantified the relationship between phenotypes and intertidal living. Likewise, the diversity of reproductive traits and parental care in intertidal fishes has yet to be compared quantitatively with habitat. We examine the relationship of these characters in the sculpin subfamily Oligocottinae using a phylogenetic hypothesis, geometric morphometrics, and phylogenetic comparative methods to provide the first formal test of associations between fish phenotypes and reproductive characters with intertidal habitats. We show that the ability to live in intertidal habitats, particularly in tide pools, is likely a primitive state for Oligocottinae, with a single species that has secondarily come to occupy only subtidal habitats. Contrary to previous hypotheses, maximum size and presence of scales do not show a statistically significant correlation with depth. However, the maximum size for all species is generally small $(250 \mathrm{~mm}$ or less) and all show a reduction in scales, as would be expected for an intertidal group. Also contrary to previous hypotheses, we show that copulation and associated characters are the ancestral condition in Oligocottinae, with copulation most likely being lost in a single lineage within the genus Artedius. Lastly, we show that body shape appears to be constrained among species with broader depth ranges, but lineages that occupy only a narrow range of intertidal habitats display novel body shapes, and this may be associated with habitat partitioning, particularly as it relates to the degree of wave exposure.

\section{Introduction}

Intertidal habitats are often highly-productive, species rich environments (Leigh et al., 1987). changing physical conditions such as wave action, temperature, and current, as well as factors that affect homeostasis of resident organisms, such as $\mathrm{pH}$ and dissolved oxygen (Davenport \& Woolmington, 1981; Bridges, 1993; Martin, Lawson \& Engebretson, 1996). Fishes living in these areas often display common physical characteristics such as small size (Gibson, 1982) and a reduction of scales (e.g., intertidal members of Blenniidae, Gobiesocidae, Pholidae, see Chotkowski, Buth \& Prochazka, 1999; Knope \& Scales, 2013), presumably as means of coping with the unique set of challenges presented by intertidal habitats. Likewise, the body shapes of intertidal fishes appear constrained to take on one of only a few stereotypical shapes, such as elongate and eel-like (e.g., Pholidae), cylindrical and tapered (e.g., Cottoidea), or dorso-ventrally compressed (e.g., Gobiesocidae; for full descriptions see Horn, 1999).

In contrast to the somewhat predictable morphological characteristics of intertidal fishes, the reproductive biology of these species is diverse and does not show apparent patterns between intertidal and subtidal taxa (reviewed in DeMartini, 1999 and Coleman, 1999). However, our 
57 understanding of many of these morphological and reproductive patterns in intertidal fishes is

58

59

60

61

62

63

64

65

66

67

68

69

70

71

72

73

74

75

76

77

78

79

80

81

82

83

84

85

86

87

88

89

90

91

92

93

94

95

96 described and compared among or between any group(s) of intertidal fishes. A quantitative approach may shed additional light on the patterns and processes of adaptation to intertidal habitats in fishes. A phylogenetic comparative approach is one way to better understand the relationship of habitat, morphological, and reproductive characters in intertidal fishes, and the marine sculpin (family Psychrolutidae sensu Smith \& Busby, 2014) subfamily Oligocottinae is a relatively well-studied group and excellent candidate in which to do so.

The 16 species that make up Oligocottinae are found in a variety of shallow nearshore habitats across the Pacific coast of North America (Hubbs, 1926; Taranetz, 1941; Ramon \& Knope, 2008; Buser \& López, 2015). The members of this subfamily occupy a range of subtidal and intertidal habitats, with varying degrees of intertidal occupation across species (Bolin, 1944; Lamb \& Edgell, 1986; Mecklenburg, Mecklenburg \& Thorsteinson, 2002). Likewise, oligocottines display a broad range of reproductive strategies ranging from copulation and internal insemination to spawning and external mixing of gametes (Petersen et al., 2005; Abe \& Munehara, 2009).

Recent studies have suggested that the diversification of Oligocottinae is associated with a shift in habitat by the group (Ramon \& Knope, 2008; Knope \& Scales, 2013). Subtidal habitats are believed to be the ancestral condition of the subfamily and the putative shift from subtidal to intertidal habitats is thought to have been followed by relatively rapid diversification of the subfamily. The shift in habitat is associated with adaptive morphological changes, which include smaller body size and fewer scales in intertidal species when compared to their deeper-dwelling relatives (Knope \& Scales, 2013). Habitat specialization is thought to have occurred within the subfamily, such that the group contains intertidal and "transitional" taxa, with the intertidal taxa being the most species rich (Ramon \& Knope, 2008).

At the heart of these results, however, is an unanswered question, namely: how does one categorize the habitat type (e.g., "intertidal") of each species? Intertidal habitats comprise a range of depths which change on daily, seasonal, and yearly cycles. Categorizing these habitats and ascribing them to a fish, which is free to move across and occupy all habitat types with every flooding tide, presents many potential pitfalls (this conundrum is reviewed in Gibson \& Yoshiyama, 1999). The ways in which fishes use these habitats ranges from intertidal residents to intertidal transients (Breder, 1948; Gibson, 1969; Thomson \& Lehner, 1976; Potts, 1980) and this continuum only further complicates the qualitative categorization of these fishes. Given these uncertainties, and the potential for arbitrary categorizations to impact the results of comparative analyses, it could be useful to take a different approach.

Many species venture into intertidal habitats during high tide but do not remain during low tides ("intertidal transients"). Conversely, some species remain in intertidal habitats throughout the tidal cycle. These "intertidal residents" are often found in special habitats during low tides, such as in tide pools or under exposed rocks, and use a suite of behavioral and physiological adaptations to cope with the challenging conditions that they present (Martin 1996, 
97 Gibson and Yoshiyama 1999, Mandic et al. 2009, Martin and Bridges 1999, Evans et al. 1999).

98 The number of prerequisite adaptations needed to survive in tide pool habitats suggests that 99 species that regularly utilize them possess at least the capacity to function as intertidal residents.

Small size (i.e., length) and a reduction of scales have been reported for many resident

101

102

103

104

105

106

107

108

109

110

111

112

113

114

115

116

117

118

119

120

121

122

123

124

125

126

127

128

129

130

131

132

133

134

135

136

intertidal species and these characters show an adaptive shift between subtidal and intertidal oligocottine sculpins (Knope \& Scales, 2013). While reproductive characters are not known to correspond to intertidal vs subtidal habitats (Coleman, 1999; DeMartini, 1999), the relationship between depth and reproductive characters has yet to be formally tested. Reproductive traits are very diverse in sculpins, particularly regarding copulation and parental care (Abe \& Munehara, 2009). While copulation is difficult to observe directly, characters that are putatively associated with this trait, such as the presence of an enlarged genital papilla, and spermatozoon morphology, are more readily observable. Parental care is also difficult to observe in many species, but has important evolutionary implications.

In this study, we forego categorization of habitat and instead infer depth ranges for each species to test whether the host of morphological and reproductive traits putatively linked to species in intertidal habitats in fact correlate with depth. To do so, we construct a phylogenetic hypothesis of the subfamily Oligocottinae using previously published molecular sequence data and use ancestral state reconstruction and phylogenetic comparative methods to test the relationship between depth range and morphological, reproductive, and body shape characters in the group.

\section{Materials \& Methods}

\section{Phylogenetic framework}

We constructed a phylogenetic framework using previously reported DNA sequences from all oligocottine species (sample size per species: 1-9 individuals, median 5) and several outgroups from the cottoid families (sensu Smith \& Busby, 2014): Agonidae ( $\mathrm{n}=6 \mathrm{spp}$.), Cottidae $(\mathrm{n}=1$ sp.), Hexagrammidae ( $n=1$ spp.), Psychrolutidae ( $n=11$ spp.), and Rhamphocottidae ( $n=1$ sp.). These outgroup taxa are consistent with the most recent phylogenetic hypotheses of broader cottoid relationships (Knope, 2013; Smith \& Busby, 2014). This dataset is accessible on Genbank (accession numbers KP826911-KP827632, see Supplementary Table 1) and contains sequence data from eight molecular loci: one mitochondrial protein-coding locus (Cytochrome c oxidase, COI), two nuclear introns [exon-primed intron crossing (EPIC) locus 1777E10 and EPIC locus 4174E20] and five protein-coding nuclear loci [early growth response protein 1 (EGR1); mixed-lineage leukemia (MLL); patched domain-containing protein 1 (ptchd1); Rhodopsin; and Sushi, von Willebrand factor type A, and pentraxin domain-containing 1 (SVEP). Multiple sequence alignments (MSAs) for each locus were generated in ClustalW (Larkin et al., 2007). Alignments were visually inspected, trimmed, and concatenated in Mesquite v3.2 (Maddison \& Maddison, 2016). The best fitting model of molecular evolution for each locus was identified using the Akaike information criterion (Akaike, 1973; Posada \& 
137 Buckley, 2004), with the model comparison routines implemented in MrModeltest v2 (Nylander, 138 2004).

139 The molecular dataset contains multiple representatives for each species, so we estimated 140 a species tree using the multispecies coalescent model (Heled \& Drummond, 2010) in BEAST 141 v1.8.2 (Drummond et al., 2012). A species set was defined, based on the results of recent 142 phylogenetic hypotheses (Knope, 2013; Smith \& Busby, 2014), for the superfamily Cottoidea, 143 which contains all taxa included in the dataset except Hexagrammos lagocephalus, which was 144 treated as an outgroup. The species of each sampled individual in the dataset was assigned as a 145 discrete trait. These species assignments were tested and validated in (Buser \& López, 2015). For 146 each locus, the model of molecular evolution yielding the lowest AIC value (as calculated in 147 MrModeltest) was applied. The rate of molecular evolution was modeled as an uncorrelated 148 lognormal relaxed clock (Drummond et al., 2006) and was unlinked across all loci. All tree models share a birth-death speciation tree prior with a piecewise linear and constant root population size model and a UPGMA starting tree. Four independent analyses were run for 200 million generations each and were sampled every 20,000 generations. MCMC logs were visualized using Tracer v1.6 (Rambaut et al., 2014) to determine convergence and an appropriate number of generations to discard as burn-in. Burn-in was removed and trees combined using LogCombiner v1.7.5 (Drummond \& Rambaut, 2007). The phylogeny was pruned in the R statistical environment (R Development Core Team 2015) using the "extract.clade" function from the package "ape" (Paradis, Claude \& Strimmer, 2004) to only include members of the subfamily Oligocottinae plus the outgroup taxon Chitonotus pugetensis. An R script, "LitorallyAdaptiveScript.R," detailing these commands and all other operations performed in R, along with all pertinent data (phylogeny, data matrix, etc.) is available in the Supplementary Materials in the folder "LitorallyAdaptive_PeerJ_Rfolder."

161

162

\section{Character coding}

164

To understand the relationship between a species' depth preferences and its size, reproductive habits, or scale patterns, we coded the following characters from previous studies and, where

166 possible, verified our findings by examining museum specimens and/or collection data

167 (summarized in Table 1):

1. Depth range (Continuous). Collection data for all specimens of each species of Oligocottinae and the outgroup taxon C. pugetensis were collated from museum records from the following natural history collections: University of Alaska Museum (UAM), University of British Columbia Beaty Biodiversity Museum (UBCBBM), University of Washington Burke Museum Fish Collection (UW), Oregon State University Fish Collection (OS), California Academy of Sciences (CAS), Natural History Museum of Los Angeles County (LACM),

175 Marine Vertebrates Collections (SIO). These records were accessed through institution-specific 176 
177 Arctos.Database.Museum, and FishNet2.org (see Supplementary Table 2 for all museum records 178 analyzed). For each species, we extracted collection depth data from all museum holdings of 179 adult specimens for which it had been recorded. Some collection depths are recorded as a range, 180 in these cases, we used the maximum depth in the range. Where the collection depth and/or 181 locality is described as "tide pool," "intertidal," etc., we assigned a collection depth of $0 \mathrm{~m}$. To 182 lessen the effects of outliers, we selected a depth range (i.e., minimum depth and maximum 183 depth) for each species that includes $95 \%$ of museum collection depths (illustrated in Figure 1).

184 For the purposes of this study, we will refer to this depth range as the range where each species is 185 "commonly" collected. To verify these depth ranges, maximum and minimum depth records for 186 each species were cataloged and cross-examined from multiple sources (Bolin, 1944; Miller \& 187 Lea, 1972; Eschmeyer, Herald \& Hammann, 1983; Mecklenburg, Mecklenburg \& Thorsteinson, 188 2002; see Supplementary Table 3). Where these previously published depth maxima and minima 189 disagree, we chose the median value for each. Many of these ranges include only imprecise 190 descriptions such as "tide pools" and "intertidal areas." In these cases, we assigned a minimum 191 depth value of $0 \mathrm{~m}$ and a maximum depth value of $2 \mathrm{~m}$.

192 2. Tide pool occupancy (Presence, absence). We noted which taxa were explicitly 193 collected from tide pools in museum collection data, in previously published depth ranges, and in 194 primary literature.

195 3. Length (Continuous). Maximum recorded length of each species was cataloged and 196 cross-examined from multiple sources (Bolin, 1944; Miller \& Lea, 1972; Eschmeyer, Herald \& 197 Hammann, 1983; Mecklenburg, Mecklenburg \& Thorsteinson, 2002; Knope \& Scales, 2013). 198 Where sources disagreed, we used the median value.

199 4. Squamation (Presence, absence). For the purposes of this study, squamation is defined 200

201

202

203

204

205

206

207 as any dermal ossification outside of the lateralis system. This includes scales, prickles, and scutes. The evolution of scale types in sculpins is poorly understood, but what is known suggests that the modified scales found in Oligocottinae may each represent an equal number of evolutionary steps away from the ancestral ctenoid scale type, with the latter not represented in any extant cottoid (Jackson, 2003). We therefore feel that in the context of this study it is unjustifiable to discriminate between scale types in oligocottines until further study indicates otherwise. Presence of squamation was coded from descriptions in the literature (Bolin, 1944; Begle, 1989; Mecklenburg, Mecklenburg \& Thorsteinson, 2002; Jackson, 2003).

208 5. Enlarged genital papilla (Presence, absence). This character was coded directly from 209 descriptions in the literature (Bolin, 1944; Mecklenburg, Mecklenburg \& Thorsteinson, 2002).

2106 Spermatozoon morphology (Oval, intermediate, slender). Character states were 211 adapted from descriptions in the literature (Hann, 1930; Petersen et al., 2005; Koya et al., 2011). 212 Slender sperm morphology is associated with internal insemination in many groups of fishes 213 (Mattei, 1991). Petersen et al. (2005) confirmed this observation in Oligocottinae by 214 demonstrating that spermatozoa with a slender-type morphology are active only in seawater that 215 has been diluted to approximate the osmolality of ovarian fluid in these sculpins, while 216 spermatozoa with oval-type morphology are active in both dilute and full-strength seawater. This 
217 suggests that slender-type spermatozoon morphology is indicative of obligate insemination, but 218 oval-type morphology indicates the capacity for external mixing of gametes (i.e., spawning).

$2197 . \quad$ Copulation (Presence, absence). For the purposes of this study, copulation is defined as 220 the transfer of sperm from a male into the ovary of a female. The presence of copulation, where 221 known, was determined from descriptions found in the literature (Bolin, 1941; Morris, 1952, 222 1956; Hubbs, 1966; Misitano, 1980; Petersen et al., 2005; Abe \& Munehara, 2009).

223 8. Parental care (Presence, absence). For the purposes of this study, egg guarding by one 224 or both parents is considered parental care. The presence of parental care, where known, was 225 determined from a review of behavioral descriptions from previous literature (Morris, 1952; 226 Hubbs, 1966; Petersen et al., 2005; Abe \& Munehara, 2009).

227

228

229

230

231

232

233

234

235

236

237

238

239

240

241

242

243

244

245

246

247

248

249

250

251

252

253

254

255

256

\section{Character mapping and ancestral state reconstruction}

To visualize the inferred evolutionary history of characters, we performed ancestral state reconstruction (ASR) of each character examined in this study. For discrete characters, we used maximum likelihood (ML) with a Markov k-state 1 parameter (Mk1) model of evolution (Lewis, 2001), implemented in Mesquite. The evolutionary history of continuous characters was inferred using ML in the R statistical environment with functions from the package "phytools" (Revell, 2012; see "Character mapping and ancestral state reconstruction" section in "LitorallyAdaptiveScript.R" in Supplementary Folder "Litorally_Adaptive_PeerJ_Rfolder").

\section{Body shape analysis}

Qualitative assessment of body shape in intertidal fishes has not only shown differences in the shape of some intertidal species compared to their subtidal relatives (e.g., Hypsoblennius spp; Thomson \& Lehner, 1976), but also that many groups of intertidal fishes (including intertidal sculpins) have converged on a small number of stereotypical body shapes (reviewed in Horn, 1999). While thought provoking, these observations have yet to be tested using quantitative methods. We used landmark-based geometric morphometrics to describe and compare the body shape of each species in this study and test for correlation between body shape and the depth at which each species occurs. Body shape data were collected from digital photographs of the lateral view of museum specimens of each species. Photography followed the phototank method of Sabaj Pérez (2009). To minimize the likelihood of introducing variation due to photographic artifacts (i.e., image distortion), lighting, distance to the subject, focal length, camera angle, and camera settings (e.g., aperture) were kept constant. We photographed 115 specimens, representing all 16 species in Oligocottinae plus the outgroup taxon C. pugetensis. Sample size per species ranges from 2 to 15 individuals, median six (Table 2). To capture overall head and body shape, landmarks were adapted from those described in previous studies of sculpin body shape (Strauss \& Bookstein, 1982; Strauss \& Fuiman, 1985). Preliminary analysis revealed a high frequency of distended stomachs and upturned caudal peduncles, presumably from prior feeding and preservation (respectively), so landmarks that appeared to be influenced by these variables were not included. Thirteen landmarks were ultimately used in this study (Fig. 2). We 
257

258

259

260

261

262

263

264

265

266

267

268

269

270

271

272

273

274

275

276

277

278

279

280

281

282

283

284

285

286

287

288

289

290

291

292

293

294

295

296

297

298

used tps-Dig2.2 (Rohlf, 2007) to locate the landmarks on each specimen from the digital photographs. To compare body shape across the group, landmark configurations were Procrustes superimposed using MorphoJ v1.06 (Klingenberg, 2011). The aligned landmark coordinates were used to calculate a covariance matrix on which we performed a principal component analysis (PCA) in MorphoJ. The number of significant principal component axes was calculated using the broken stick method (Frontier, 1976; Jackson, 1993; Legendre \& Legendre, 2012), implemented with the "screeplot.cca" function in the R package "vegan" (Oksanen et al., 2017). The significant principal component axes were used to interpret overall shape variation and visualize the distribution of species in body shape morphospace. To visually check for evidence of morphological convergence or divergence, we projected phylogenetic relatedness into the principal component morphospaces and inferred states of each significant PC axis for each ancestral node (i.e., phylomorphospace analysis; Sidlauskas, 2008) using the "phylomorphospace" function in the R package "phytools" (Revell, 2012; see "Body shape analysis" section in "LitorallyAdaptiveScript.R" in Supplementary Folder “LitorallyAdaptive_PeerJ_Rfolder").

\section{Depth correlation analysis}

For both museum records and previously published depth ranges, preliminary results indicated that, while there is considerable variability in the maximum collection depth of each species in Oligocottinae, all species share a minimum recorded depth of zero meters. Given this invariability in minimum depth, we chose to use only maximum depth as our depth variable for regression analysis. We used phylogenetic generalized least squares regression (PGLS) implemented using the "gls" function in the R package "nlme" (Pinheiro et al., 2015) to test for a linear correlation between depth and each maximum length. To account for potential variability in trait evolution (e.g., Brownian motion, selection, etc.), we tested three alternate singleparameter correlation structures supplied in the R package "ape" (Paradis, Claude \& Strimmer, 2004) in each of our regression models: a Brownian motion model with correlation due to phylogenetic relatedness represented by Pagel's lambda (Pagel, 1994, 1999), which we estimated using ML; a Brownian motion model with the rate of evolution (accelerated or decelerated) estimated using ML; and a single optimum (i.e., stabilizing selection) Ornstein-Uhlenbeck (OU) model (Felsenstein, 1988; Hansen, 1997) with the strength of attraction towards the optimum represented by alpha and estimated using ML. The best fitting model for each regression was determined by comparing AIC values. We also tested for a statistically significant difference in the average minimum or maximum depth between each state of the binary characters: presence of scales and presence of a genital papilla using phylogenetic analysis of variance (ANOVA) implemented using the "aov.phylo" function from the R package "geiger" (Harmon et al., 2007).

One of our hypotheses is that shallow-dwelling species show convergent morphology differing from that of their subtidal sister taxa. To test for convergent or divergent evolution of body shape, we used a stepwise model-fitting approach, "surface," that detects shifts and convergence in phenotypic optima (Ingram \& Mahler, 2013). In this approach, each optimum contributes a parameter to an OU process of evolution. The "surface" method finds the maximum-likelihood estimate of the number and location of phenotypic optima under the OU 
299

300

301

302

303

304

305

306

307

308

309

310

311

312

313

314

315

316

317

318

319

320

321

322

323

324

325

326

327

328

329

330

331

332

333

334

335

336

337

338

model and collapses similar phenotypic optima together if it improves the AIC score (Ingram \& Mahler, 2013). Phenotypic convergence is indicated when independent lineages share a common optimum. These analyses were conducted in the R environment using functions from the package "surface" (Ingram \& Mahler, 2013).

To visualize only the aspects of body shape that covary with depth, a partial least squares analysis (PLS) was conducted on a matrix of depth variables (minimum depth and maximum depth) and Procrustes-aligned shape variables (Rohlf \& Corti, 2000). This analysis was conducted in MorphoJ and in R using functions from the package "geomorph v2.0" (Adams \& Otárola-Castillo, 2013). In both cases, the significance of the covariance was tested using a permutation test with 10,000 iterations (see "Correlation with depth" section in "LitorallyAdaptiveScript.R" in Supplementary Folder "LitorallyAdaptive_PeerJ_Rfolder").

\section{Results}

\section{Character mapping and ancestral state reconstruction}

The trimmed, concatenated MSA dataset spans 4695 aligned nucleotide sites, containing 1037 variable sites. The topology of the Bayesian maximum clade credibility (MCC) phylogeny produced herein is identical to the topology of the MCC phylogeny reported in Buser \& López (2015), with similar levels of support for each clade (Figure 3). As noted in Buser \& López (2015), this topology is similar to that of other molecular-based phylogenetic inferences of Oligocottinae (i.e., Ramon \& Knope, 2008; Knope, 2013), but has substantially higher support values (i.e., Bayesian posterior probability) for many of the inferred relationships. We will use the classification and taxonomy suggested by Buser \& López (2015) for discussion of the interrelationships of oligocottine sculpins.

The outgroup taxon, C. pugetensis, rarely (if ever) occurs in intertidal areas (Fig. 1, Table 1, Supplementary Tables 3 \& 4). However, apart from L. hirundo, all the constituent species of Oligocottinae are regularly found in intertidal habitats and both museum records and published depth ranges include tide pools in the common collection depth or depth range data for all oligocottine species but L. hirundo (Fig. 1, Table 1, Supplementary Tables $3 \& 4$ ). There is also explicit discussion of tide pool and intertidal occupancy for all oligocottine species except $L$. hirundo in the primary literature (Supplementary Table 3). However, while the occupation of intertidal and subtidal habitats is often portrayed as an either/or scenario, there is considerable variation in the maximum depth at which each species occurs (Fig. 1, Table 1). Generally though, all oligocottine species occur at relatively shallow depths: none is commonly collected at depths greater than $55 \mathrm{~m}$, most (12/16 spp.) are not commonly collected below $25 \mathrm{~m}$ (though there is some discrepancy between the museum collection data and the published depth ranges for A. corallinus and A. fenestralis), and four (published ranges) to seven (museum depth data) species are common only in very shallow (i.e., $2 \mathrm{~m}$ depth or less) habitats (Table 1). There is considerable disagreement between the museum collection data and the published depth range for A. notospilotus, C. acuticeps, C. analis, and L. hirundo. In each case, published depth ranges 
339

340

341

342

343

344

345

346

347

348

349

350

351

352

353

354

355

356

357

358

359

360

361

362

363

364

365

366

367

368

369

370

371

372

373

374

375

376

377

378

indicate a maximum depth that is $>10 \mathrm{~m}$ deeper than the depths where these species have been commonly collected in museum holdings (Supplementary Tables 3 and 4). However, the depth ranges are otherwise largely congruent, and the differences between the two datasets are minimal (compare depth range values in Table 1 and Supplementary Table 3). All remaining analyses show identical outcomes when using either the common museum collection depth data or the previously published depth range data for each species. Given the congruence of the datasets, the indistinguishable outcome of using one over the other, and the more verifiable nature of the museum collection records, we present the results of the remaining analyses using only the common museum collection depth range of each species.

Predictably, the ASR of minimum depth shows that the most recent common ancestor (MRCA) of Oligocottinae likely occurred in shallow habitats (ML estimate: $1 \mathrm{~m} ; 95 \%$ confidence interval: $0 \mathrm{~m}, 2 \mathrm{~m}$ ). Ancestral state reconstruction of tide pool occupancy shows that with extremely high proportional likelihood (0.9988) the MRCA of Oligocottinae occurred in tide pools. In fact, even the MRCA of the Leiocottus lineage was likely ( 0.9215 proportional likelihood) capable of living in tide pools (Supplementary Figure 1). Thus, the absence of tide pool occupation in L. hirundo likely represents a derived state. The ASR of maximum depth suggests that the MRCA of Oligocottinae occurred down to only moderate depths (ML estimate: $23 \mathrm{~m} ; 95 \%$ confidence interval: $2 \mathrm{~m}, 44 \mathrm{~m}$; see Fig. 4) and suggests that the habitation of only very shallow-water habitats (maximum depth $=2 \mathrm{~m}$ or less) seen in Oligocottus maculosus, $O$. rimensis, and $O$. snyderi and in all members of the subgenus Clinocottus (Blennicottus) represents a derived state (see Table 1, Fig. 4). However, given the uncertainty of the ML estimates of maximum depth at each node (Fig. 4), and the uncertain phylogenetic relationships of Blennicottus, Leiocottus, and Oligocottus lineages (Fig. 1), it is not possible to claim with confidence the number of transitions that may have occurred within the subfamily.

Maximum length shows no obvious relationship with depth in Oligocottinae (illustrated in Fig. 4). All species (including the outgroup) are relatively small (none longer than $250 \mathrm{~mm}$ ), most (12/16 spp.) do not grow longer than $150 \mathrm{~mm}$, and seven species do not grow longer than $100 \mathrm{~mm}$ (Table 1). The ASR of maximum length suggests that the MRCA of Oligocottinae was small $(132 \mathrm{~mm}, 95 \%$ confidence interval: $83 \mathrm{~mm}, 182 \mathrm{~mm})$, but like maximum depth, the uncertainty of the ML estimates at each node precludes additional inference into the diversification of this trait (Supplementary Figure 2).

Squamation is common among members of Oligocottinae but is completely absent in two clades: the subgenus Clinocottus (Blennicottus), and the clade in Oligocottus made up of $O$.

maculosus, O. snyderi, and O. rubellio (Table 1, Supplementary Figure 3). Predictably, the ASR shows that the presence of squamation is the most likely state for the MRCA of Oligocottinae (proportional likelihood: 0.81 ), and that the absence of scales represents an independent loss of the trait in the MRCA of each of the above clades (Supplementary Figure 3). It should be noted that we inferred the evolution of squamation using an Mk1 model, which assumes that all potential changes in state are equally probable (Lewis, 2001). Given the lack of rigorous study of scale evolution in sculpins, specifying a more complex model is not warranted. However, it is 
379 our opinion that re-acquisition of squamation is an extremely unlikely evolutionary scenario in 380 oligocottine sculpins (i.e., less probable than the loss of squamation) and thus the proportional 381 likelihood of the presence of scales for the ancestral nodes in Oligocottinae should be taken as a

382

383

384

385

386

387

388

389

390

391

392

393

394

395

396

397

398

399

400

401

402

403

404

405

406

407

408

409

410

411

412

413

414

415

416

417

418 conservative estimate.

An enlarged genital papilla is found in all but five species of Oligocottine sculpins (Fig. 5). The ASR shows with high proportional likelihood $(>0.98)$ that this character was present at all ancestral nodes except those within the clade composed of the members of the genus Artedius. Within Artedius, an enlarged genital papilla was likely lost in the MRCA of the clade containing A. corallinus, A. fenestralis, A. lateralis, and A. notospilotus (Fig. 5). An independent loss of the enlarged genital papilla occurred in the oligocottinin species Orthonopias triacis.

The distribution of spermatozoon morphology follows a pattern similar to that of the enlarged genital papilla. Outside of the clade composed of members of the genus Artedius, slender-type spermatozoa are present in all Oligocottine sculpins and, with high proportional likelihood ( $>0.90)$, this is the state at all ancestral nodes (Fig. 5). Within Artedius, an oval-type spermatozoon likely evolved in the MRCA of the clade containing A. corallinus, A. fenestralis, A. lateralis, and A. notospilotus. Artedius harringtoni possess an intermediate spermatozoon morphology and is the only oligocottine to do so (Fig. 5). With one notable exception, this shows that all species with a slender-type spermatozoon morphology (which in other species is known to function only in ovarian fluid) also possess an enlarged genital papilla, which is presumably used in copulation. The exception to this observation is the species Orthonopias triacis, which does not possess an enlarged genital papilla, but does possess a slender-type sperm morphology.

Though not known for all species in Oligocottinae, the distribution of copulatory behavior closely follows that of spermatozoon morphology, where copulating species possess either slender or intermediate-type spermatozoon morphology, and non-copulating species possess only oval-type spermatozoon morphology (illustrated in Fig. 5; see also Supplementary Figure 4). The ASR of this character shows that, with high proportional likelihood $(>0.95)$, presence of copulation is the likely state for all ancestral nodes outside of the clade composed of the members of the genus Artedius. Within Artedius, copulation was likely lost in the MRCA of the clade containing $A$. corallinus, $A$. fenestralis, A. lateralis, and A. notospilotus. This finding reinforces the observations of Mattei (1991) and Petersen et al. (2005) who each show that slender-type sperm morphology is indicative of copulating species. Once again, Orthonopias triacis presents a noteworthy case as there is evidence of copulation for the species and the species possesses a slender-type spermatozoon morphology, yet the species lacks an enlarged genital papilla or other known intromittent organ (Fig. 5).

The presence or absence of parental care has been described in less than half of all oligocottine species (6/16 spp.), but follows a similar pattern to those seen in other reproductive characters in the group, where members of the genus Artedius tend to differ from all other species. In this case, parental care is observed only in members of Artedius (Fig. 6). The ASR shows that parental care was likely present in the MRCA of Artedius, while a lack of parental care is the most likely state for the MRCA of the tribe Oligocottini. However, given the 
419

420

421

422

423

424

425

426

427

428

429

430

431

432

433

434

435

436

437

438

439

440

441

442

443

444

445

446

447

448

449

450

451

452

453

454

455

456

457

458

substantial amount of missing data for this trait, the ASR is subject to change with the addition of new observations.

\section{Body shape analysis}

Observed body shape variation was captured by two significant principal components, which cumulatively describe $70 \%$ of the total variance. We used an outline of a specimen of Clinocottus analis to visualize shape change represented by each PC axis in MorphoJ (Fig. 7). Principal component (PC) 1 (52\% of total observed variance) describes antero-posterior elongation/compression of the head and mouth as well as the relative size of the eye. Principal component 2 (19\% of total observed variance) captures dorso-ventral elongation/compression of the body, the shape of the eye, and the slope of the snout.

There is no clear evidence of a consistent relationship between the minimum depth or maximum depth of a species and its morphology, nor evidence of morphological convergence among shallow or deep-ranging species (Fig. 8). Species with deeper ranges appear to be constrained to a common morphospace, while species that inhabit only shallow depth ranges (e.g., Oligocottus spp., Clinocottus (Blennicottus) spp.) appear to occupy novel and distinct areas of morphospace (Fig. 8). This observation is supported by the results of the "surface" analysis, which inferred three optima for body shape in the morphospace described by the significant PC axes: one for members of the genus Oligocottus plus Orthonopias triacis, one for members of the subgenus Clinocottus (Blennicottus), and a third that is occupied by all other oligocottines (Supplementary Figure 5). However, there is no clear pattern in terms of the direction of the divergence in morphospace of these taxa. Interestingly, two of the optima are occupied almost entirely by taxa that are found exclusively in shallow water (i.e., Clinocottus (Blennicottus) and all but one species of Oligocottus), while the remaining optimum is made up almost exclusively of deeper-ranging taxa (the exception being $C$. (O.) acuticeps. Here again Orthonopias triacis is remarkable in that it is a deeper-ranging species, but appears to be drawn to the phenotypic optimum occupied otherwise exclusively by the genus Oligocottus.

\section{Depth correlation analysis}

No morphological, reproductive, and body shape variables examined in this study show a significant correlation with maximum depth. The phylogenetic generalized least squares regression showed no significant linear correlation between depth and maximum length, and the phylogenetic ANOVA showed no statistically significant difference in average maximum depth between the binary character states of: presence of squamation ( $p$-value $>0.15$ ) or presence of an enlarged genital papilla ( $p$-value $>0.70$ ). Likewise, the results of the PLS analysis were identical in MorphoJ and in R, and failed to show a statistically significant correlation between body shape and depth range ( $\mathrm{p}$-value $>0.05$ ). However, the analysis did reveal a few interesting observations: species that are restricted entirely to shallow water tend to display greater morphological diversity than those that range into deeper water, but generally have smaller eyes, smaller mouths, terminal placement of the mouth, and more robust bodies, while deeper-ranging 
459

460

461

462

463

464

465

466

467

468

469

470

471

472

473

474

475

476

477

478

479

480

481

482

483

484

485

486

487

488

489

490

491

492

493

494

495

496

497

498

species tend to have larger eyes, larger mouths, subterminal placement of the mouth, and dorsoventrally compressed bodies (Fig. 9).

\section{Discussion}

The results of our study show support for some previous hypotheses of the diversification of Oligocottinae and the general evolution of intertidal fishes in that, excepting L. hirundo, all oligocottines regularly occur in tide pools, and all show small bodies and few scales. However, our results do not support previous hypotheses regarding the evolution of reproductive modes in oligocottines or, to a certain extent, sculpins in general. In some cases, our conclusions directly oppose those made by previous authors. We discuss these results and some plausible explanations for our congruous and incongruous conclusions below.

\section{Squamation, length, and depth}

The subfamily Oligocottinae should be thought of as a clade of intertidal-occurring fishes and the ability to live in intertidal depths and specialized intertidal habitats such as tide pools is likely the ancestral state of the group. However, this ability to live in tide pools does not preclude residency in other habitat types within the same species, as many of the extant and ancestral species are capable of living in a variety of depths in addition to the intertidal ones. Thus, the diversification of Oligocottinae should be characterized as occurring within a habitat range that includes both subtidal and intertidal habitats. This may explain the general lack of correlation between depth the other characters examined in this study.

Small maximum size and a reduction in scales have been noted as common features of intertidal fishes by previous authors (Gibson, 1982; Knope \& Scales, 2013), and while we found no evidence to support these hypotheses within Oligocottinae, oligocottines as a whole may in fact offer support. All oligocottines are small (none longer than $250 \mathrm{~mm}$ ), and all show a reduction in scales when compared to a "typical" scaled member of Cottales, such as Oxylebius pictus (see Jackson, 2003). Outside of the lateral line, the most heavily scaled oligocottines possess only modified scales in a narrow band on the body along each side of the dorsal fins and on the dorsal surfaces of the head and caudal peduncle (e.g., Orthonopias triacis; see descriptions in Bolin, 1944; Jackson, 2003). Others possess highly reduced scales in the form of prickles (e.g., Clinocottus (Clinocottus) analis; see description in Bolin, 1944). It is presumed that the primary reason scales are often reduced in intertidal fishes is to promote cutaneous respiration, which is dependent on well vascularized skin that is free from obstructions (Feder \& Burggren, 1985; Martin \& Bridges, 1999). Within Oligocottinae, it may simply be the case that the highly-reduced scales seen in the group do not cover enough surface area to interfere with cutaneous respiration in a meaningful way. Or perhaps that cutaneous respiration is restricted to only certain areas, such as the head (as seen in Coryphoblennius galerita, see Zander, 1972), or buccal chamber (reviewed in Bridges, 1993). This may explain the presence of scales within the group, and the fact that even the most heavily scaled members of Oligocottinae occur intertidally 
499

500

501

502

503

504

505

506

507

508

509

510

\section{1}

512

513

514

515

516

517

518

519

520

521

522

523

524

525

526

527

528

529

530

531

532

533

534

535

536

537

538

and in tide pools (Fig. 2). Interestingly, the one oligocottine species that does not occur intertidally (L. hirundo) possess only a few highly reduced scales in the form of a scattered patch of prickles located just posterior to the base of the pectoral fins (see Jackson, 2003). We interpret this as evidence that a reduction in scales in an ancestral condition for Leiocottus, and possibly Oligocottinae as a whole.

The evolutionary history of maximum size, depth range, and the presence of squamation all support the idea that the subfamily Oligocottinae is a primitively intertidal group. All species in this subfamily display conditions of these traits that are common in intertidal taxa, and all but one species are commonly found intertidally and explicitly in tide pools. These findings support those of previous studies which found Oligocottinae to represent an intertidal radiation (Ramon \& Knope, 2008; Knope \& Scales, 2013).

\section{Body shape and depth}

While the body shape of deeper-ranging species is relatively conserved, groups that occupy only intertidal areas appear to be exploring novel areas of morphospace (Figure 8, Supplementary Figure 5). This is most pronounced in members Oligocottus and the subgenus Clinocottus (Blennicottus), where the two groups each occupy a morphological optimum that is distinct from each other and from all but one other oligocottine (i.e., the enigmatic $O$. triacis). The morphological distinctiveness of Clinocottus (Blennicottus) is readily apparent, even to the casual observer, with antero-posteriorly compressed heads and highly robust bodies and fins (see illustrations in Bolin, 1944). The constituent species of this subgenus occur most abundantly in steep, rocky habitats with high wave exposure and are often the only oligocottine species found in these areas (T. Buser pers. obs.; Green, 1971; Yoshiyama, 1981; Yoshiyama, Sassaman \& Lea, 1986; Mgaya, 1992, see also descriptions in Eschmeyer, Herald \& Hammann, 1983; Lamb \& Edgell, 1986; Mecklenburg, Mecklenburg \& Thorsteinson, 2002). The blunt heads and short, stocky bodies of these species are also seen in other intertidal fishes occupying similarly exposed, rocky habitats and may reflect a common evolutionary response to the physical demands of living in such areas (Kotrschal, 1988, 1989; Thomson, Findley \& Kerstitch, 2010, reviewed in Kotrschal, 1999). If the diverse morphologies seen among intertidal specialist clades are reflective of their respective habitat partitions, it may also be the case that the constrained morphologies seen in deeper-ranging taxa reflect a kind of stabilizing selection of generalist traits that are optimal for occupying a comparatively wide variety of habitats. The relatively high diversity of morphotypes seen in shallow vs deep-ranging species may mask morphological traits that are in fact associated with depth, as is suggested by the results of our PSL analysis (Fig. 9). However, the lack of statistical significance of this trend warrants caution on interpretation of this finding until the question can be revisited with additional taxa.

\section{Reproduction}

While reproductive characters do not show any correlation with depth range in Oligocottinae, the evolution of these traits in the subfamily may offer new insight into the evolution of reproductive 
539 modes in cottoids. Copulation in oligocottines is associated with an enlarged genital papilla and a

540 slender-type spermatozoon morphology. These traits are broadly distributed in Oligocottinae and

541 are likely the ancestral state of the subfamily (Fig. 5). Importantly, the absence of copulation and

542 associated traits in most members of the genus Artedius represents a loss and is thus a derived

543 state. This finding runs counter to previous hypotheses of the evolution of reproductive modes in

544 sculpins, which interpreted the seemingly scattered distribution of copulation in cottoids as

545 indicative of parallel or convergent evolution of copulation from non-copulating ancestors (Abe

$546 \&$ Munehara, 2009; Muñoz, 2010). Under this paradigm, Petersen et al. (2005) suggests that the

547 ability of the oval-type sperm morphology (uniquely capable of functioning well in seawater and

548 ovarian fluid, seen in non-copulating members of Artedius) to function in ovarian fluid

549 represents a derived condition and concludes that the presence of this trait in most members of

550 Artedius represents an evolutionary step towards copulation in the group. We conclude the

551 opposite of Petersen et al. (2005), and suggest that rather than the sperm's ability to function in

552 ovarian fluid, it is in fact the sperm's ability to function in seawater that is a derived state and

553 this, along with the loss of an intromittent organ, represents an evolutionary step away from

554 copulation within Artedius.

555 A reduction or loss of the enlarged genital papilla is seen in other oligocottines as well.

556 Critically, however, these species maintain a slender-type spermatozoon morphology and, where

557 known, copulation. For example, while most oligocottines possess genital papillae that are quite

558 large and robust, males in the genus Oligocottus possess papillae that are uniquely small, gracile,

559 and thread-like (Supplementary Figure 6). Also unique to the males of this genus are

560 modifications of the anterior portion of the anal fin (Supplementary Figure 7) which, where

561 known, is used for grasping females during copulation (O. snyderi; Morris, 1956). It is possible

562 that the added security and stability during copulation provided by the prehensile anal fin rays

563 has rendered the large genital papilla seen in other oligocottines redundant. The other example of

564 a reduction in the size of the male genital papilla is seen in Orthonopias triacis, where males lack

565 an intromittent organ altogether, yet also possess slender-type sperm morphology and are known

566 to copulate. Males of this species possess enlarged pelvic fins that face inwardly "palm to palm,"

567 and project postero-ventrally from a "pedunculated" base (Bolin, 1944). Perhaps these highly

568 modified, sexually dimorphic pelvic fins are used in a grasping manner that, like in Oligocottus,

569 is used to aid in copulation and has eliminated the need of a large, robust male genital papilla.

570 Copulation without the use of an intromittent organ is seen in at least one other member of

571 Cottales, the sea raven (Hemitripterus villosus). In this species, males are not known to possess

572 any putative grasping organs. Instead, the female everts her genital tract, which is covered in

573 mucus, and the male ejaculates onto it, whereby the sperm become entrained in the mucus and

574 enter the female when she inverts her genital tract (Munehara, 1996).

575 Our results show that while the presence of an enlarged male genital papilla is a likely

576 indicator of copulation, the absence of an intromittent organ does not necessarily indicate the

577 absence of copulation. Furthermore, our results show that non-copulating species may evolve

578 from copulating ancestors. Given the widespread distribution of copulation and/or an enlarged 
579 genital papillae within Cottoidea (Abe \& Munehara, 2009; Muñoz, 2010), we suggest that 580 copulation and associated traits may have evolved much earlier in cottoids than has been

581 previously estimated. Perhaps the seemingly disparate distribution of copulation in cottoids is not 582 due to many independent evolutions of copulation, but rather to a single early evolution of 583 copulation and multiple subsequent losses of the trait. Given the suite of complex physiological 584 and behavioral traits associated with copulation in sculpins (e.g., internal gamete association 585 with delayed fertilization, see Munehara, Takano \& Koya, 1989, 1991; Munehara et al., 1997; 586 Petersen et al., 2005), the independent loss of copulation by certain lineages would, in our 587 opinion, be a far simpler explanation for the modern distribution of the trait than would the 588 independent evolution of copulation and all associated characters.

589

590

591

592

593

594

595

596

597

598

599

600

601

602

603

604

605

606

607

608

609

610

611

612

\section{Parental care}

Like other reproductive traits, the distribution of parental care in Oligocottinae does not appear to be related to the distribution of depth ranges. Rather, only members of the genus Artedius display parental care. Strong phylogenetic signal of parental care has been reported for other groups as well (reviewed in Coleman, 1999), but this does not provide a satisfying explanation for why Artedius differs from all other oligocottines in this trait. It is interesting to note that parental care shows an almost inverse distribution to oval-type sperm morphology (i.e., obligate copulation; see Figs. 5 and 6), but the limited sample size and degree of missing data for parental care make this a tenuous connection. Many other non-copulating sculpins also display parental care (e.g., Hemitripterus spp., Enophrys bison, Myoxocephalus spp., Cottus spp.), but this trait is also seen in some copulating species, including Artedius harringtoni (Abe \& Munehara, 2009). Clearly, more research is needed to better understand the evolution of parental care in cottoids, and its relationship with other aspects of their complex reproductive biology.

\section{Conclusions}

Considering the depth ranges rather than previously published habitat categorizations of oligocottine sculpins shows substantial overlap of almost all species in intertidal habitats. This understanding of the group agrees with our findings that all oligocottine sculpins are relatively small and bear relatively few scales, two common attributes of intertidal fishes. This finding also helps to explain why the maximum depth of the common depth range does not correlate with most of the characters examined in this study, as we would expect them to vary with depth only

613 body shape of most species with broader depth ranges appear constrained to what we interpret as 614 a generalist morphology, while most groups that inhabit a narrow, wholly-intertidal depth range 615 appear to have unique body shapes, perhaps suited to their specialized habitat partitions.

616 Likewise, we find no evidence of an association between maximum depth and reproductive 617 characters, but we do find that the evolution of these characters has likely proceeded from a 618 primitive condition of obligate copulation using an intromittent organ to a derived state of 
619 spawning and/or the loss of an intromittent organ. This sequence is the opposite direction of that 620 inferred by previous authors, but is clearly supported by the distribution of reproductive traits 621 across our phylogenetic hypothesis of the group.

622

623

624 Acknowledgements

625 Specimens were generously loaned by Katherine Maslenikov and Ted Pietsch (Burke Museum), 626 H.J. Walker (Scripps Institution of Oceanography) and Dave Catania (California Academy of 627 Sciences). We thank Brian Sidlauskas for his advice and mentorship through much of the 628 development and execution of this project. We thank the academic editor and two peer-reviewers 629 of this manuscript who provided substantial feedback and helped to improve the quality and 630 clarity of the work. We thank Matthew A. Campbell, Anne Beaudreau, Derek Sikes, Doug 631 Markle, Jay Orr, Benjamin W. Frable, and Sophie Pierszalowski for contributing considerable 632 technical support, philosophical discussion, and methodological expertise during various phases 633 of this study.

634

635 
636 References:

637 Abe T., Munehara H. 2009. Adaptation and evolution of reproductive mode in copulating cottoid 638 species. In: Reproductive Biology and Phylogeny of Fishes, Vol 8B: Part B. Science $639 \quad$ Publishers, 221-246.

640 Adams DC., Otárola-Castillo E. 2013. geomorph: an R package for the collection and analysis of 641 geometric morphometric shape data. Methods in Ecology and Evolution 4:393-399.

642 Akaike H. 1973. Information theory and an extension of the maximum likelihood principle. In:

643 Petrov BN, Csaki F eds. Proceedings of the Second International Symposium on

644 Information Theory. Budapest, 267-281.

645 Begle DP. 1989. Phylogenetic analysis of the cottid genus Artedius (Teleostei:

646 Scorpaeniformes). Copeia:642-652.

647 Bolin RL. 1941. Embryonic and early larval stages of the cottid fish Orthonopias triacis Starks 648 and Mann. Stanford Ichthyological Bulletin 2:73-82.

649 Bolin RL. 1944. A review of the marine cottid fishes of California. Stanford Ichtthyological $650 \quad$ Bulletin 3:1-135.

651 Breder CM. 1948. Observations on coloration in reference to behavior in tide-pool and other 652 marine shore fishes. Bulletin of the American Museum of Natural History 92:285-311.

653 Bridges CR. 1993. Ecophysiology of intertidal fish. In: Rankin JC, Jensen FB eds. Fish 654 ecophysiology. London: Chapman and Hall, 375-400.

Buser TJ., López JA. 2015. Molecular phylogenetics of sculpins of the subfamily Oligocottinae 656 (Cottidae). Molecular phylogenetics and evolution 86:64-74. 
657 Chotkowski MA., Buth DG., Prochazka K. 1999. Systematics of intertidal fishes. In: Horn MH, 658 Martin KLM, Chotkowski MA eds. Intertidal Fishes: Life in two worlds. San Diego: $659 \quad$ Academic Press, 297-331.

660 Coleman RM. 1999. Parental care in intertidal fishes. In: Horn MH, Martin KLM, Chotkowski 661 MA eds. Intertidal Fishes: Life in Two Worlds. San Diego: Academic Press, 165-180.

662 663

664 665

666 667

668 669

670

671

672

673

674 675 676 677

Davenport J., Woolmington AD. 1981. Behavioural responses of some rocky shore fish exposed to adverse environmental conditions. Marine \& Freshwater Behaviour \& Phy 8:1-12.

DeMartini EE. 1999. Intertidal spawning. In: Horn MH, Martin KLM, Chotkowski MA eds. Intertidal fishes: Life in two worlds. San Diego: Academic Press, 143-164.

Drummond AJ., Ho SY., Phillips MJ., Rambaut A. 2006. Relaxed phylogenetics and dating with confidence. PLoS Biology 4:e88. DOI: 10.1371/journal.pbio.0040088.

Drummond AJ., Rambaut A. 2007. BEAST: Bayesian evolutionary analysis by sampling trees. BMC evolutionary biology 7:214.

Drummond AJ., Suchard MA., Xie D., Rambaut A. 2012. Bayesian phylogenetics with BEAUti and the BEAST 1.7. Molecular biology and evolution 29:1969-1973.

Eschmeyer WN., Herald ES., Hammann H. 1983. A field guide to Pacific coast fishes: North America. Boston: Houghton Mifflin Harcourt.

Feder ME., Burggren WW. 1985. Cutaneous gas exchange in vertebrates: design, patterns, control and implications. Biological Reviews 60:1-45.

Felsenstein J. 1988. Phylogenies and quantitative characters. Annual Review of Ecology and Systematics 19:445-471. 
678 Frontier S. 1976. Étude de la décroissance des valeurs propres dans une analyse en composantes

679 principales: Comparaison avec le modd́le du bâton brisé. Journal of Experimental Marine $680 \quad$ Biology and Ecology 25:67-75.

681 Gibson RN. 1969. The biology and behaviour of littoral fish. Oceanography and Marine 682 Biology: An Annual Review 7:367-410.

683 Gibson RN. 1982. Recent studies on the biology of intertidal fishes. Oceanography and Marine 684 Biology: An Annual Review 20:363-414.

685 Gibson RN., Yoshiyama RM. 1999. Intertidal fish communities. In: Horn MH, Martin KLM, 686 Chotkowski MA eds. Intertidal fishes: life in two worlds. San Diego: Academic Press, $687 \quad 264-296$.

688 Green JM. 1971. Local distribution of Oligocottus maculosus Girard and other tidepool cottids of 689

690 691

692

693 Hansen TF. 1997. Stabilizing selection and the comparative analysis of adaptation. $694 \quad$ Evolution:1341-1351.

695 Harmon LJ., Weir JT., Brock CD., Glor RE., Challenger W. 2007. GEIGER: investigating 696 evolutionary radiations. Bioinformatics 24:129-131.

697 Heled J., Drummond AJ. 2010. Bayesian inference of species trees from multilocus data. 698 Molecular biology and evolution 27:570-580. 
699 Horn MH. 1999. Convergent evolution and community convergence: research potential using 700 intertidal fishes. In: Horn MH, Martin KLM, Chotkowski MA eds. Intertidal Fishes. 701 Academic Press, San Diego, Calif. San Diego: Academic Press, 356-372.

702 Hubbs CL. 1926. A revision of the fishes of the subfamily Oligocottinae. Occasional papers of 703 the Museum of Zoology, University of Michigan 171:1-18.

704 Hubbs C. 1966. Fertilization, initiation of cleavage, and developmental temperature tolerance of 705 the cottid fish, Clinocottus analis. Copeia:29-42.

706 Ingram T., Mahler DL. 2013. SURFACE: detecting convergent evolution from comparative data 707 by fitting Ornstein-Uhlenbeck models with stepwise Akaike Information Criterion.

$708 \quad$ Methods in Ecology and Evolution 4:416-425.

709 Jackson DA. 1993. Stopping rules in principal components analysis: a comparison of heuristical $710 \quad$ and statistical approaches. Ecology 74:2204-2214.

711 Jackson KL. 2003. Contributions to the systematics of Cottoid fishes (Teleostei: $712 \quad$ Scorpaeniformes).

713 Klingenberg CP. 2011. MorphoJ: an integrated software package for geometric morphometrics. $714 \quad$ Molecular ecology resources 11:353-357.

715 Knope ML. 2013. Phylogenetics of the marine sculpins (Teleostei: Cottidae) of the North 716 American Pacific coast. Molecular phylogenetics and evolution 66:341-349.

717 Knope ML., Scales JA. 2013. Adaptive morphological shifts to novel habitats in marine sculpin 718 fishes. Journal of evolutionary biology 26:472-482.

719 Kotrschal K. 1988. Blennies and endolithic bivalves: differential utilization of shelter in Adriatic 720 Blenniidae (Pisces: Teleostei). Marine ecology 9:253-269. 
721 Kotrschal K. 1989. Trophic ecomorphology in eastern Pacific blennioid fishes: character

722 transformation of oral jaws and associated change of their biological roles.

723 Environmental Biology of Fishes 24:199-218.

724 Kotrschal K. 1999. Sensory systems. In: Horn MH, Martin KLM, Chotkowski MA eds. 725 Intertidal fishes: life in two worlds. San Diego: Academic Press, 126-142.

726 Koya Y., Hayakawa Y., Markevich A., Munehara H. 2011. Comparative studies of testicular 727 structure and sperm morphology among copulatory and non-copulatory sculpins (Cottidae: Scorpaeniformes: Teleostei). Ichthyological research 58:109-125.

729

730

731

732

733

734

735

736

737

738

739

740

741

742

743

Lamb A., Edgell P. 1986. Coastal fishes of the Pacific Northwest. Madeira Park, BC: Harbour Publishing Company.

Larkin MA., Blackshields G., Brown NP., Chenna R., McGettigan PA., McWilliam H., Valentin F., Wallace IM., Wilm A., Lopez R. 2007. Clustal W and Clustal X version 2.0. Bioinformatics 23:2947-2948.

Legendre P., Legendre L. 2012. Numerical ecology (3rd English edition) Elsevier. Amsterdam, The Netherlands: Elsevier.

Leigh EG., Paine RT., Quinn JF., Suchanek TH. 1987. Wave energy and intertidal productivity. Proceedings of the National Academy of Sciences 84:1314-1318.

Lewis PO. 2001. A likelihood approach to estimating phylogeny from discrete morphological character data. Systematic biology 50:913-925.

Maddison WP., Maddison DR. 2016. Mesquite.

Martin KLM., Bridges CR. 1999. Respiration in water and air. In: Horn MH, Martin KLM, Chotkowski MA eds. Intertidal fishes: life in two worlds. San Diego: Academic Press, 54-78. 
744 Martin KLM., Lawson MC., Engebretson H. 1996. Adverse effects of hyposalinity from

745 stormwater runoff on the aggregating anemone, Anthopleura elegantissima, in the marine 746 intertidal zone. Bulletin of the Southern California Academy of Sciences 95:46-51.

747 Mattei X. 1991. Spermatozoon ultrastructure and its systematic implications in fishes. Canadian $748 \quad$ journal of zoology 69:3038-3055.

749 Mecklenburg CW., Mecklenburg TA., Thorsteinson LK. 2002. Fishes of Alaska. Bethesda: $750 \quad$ American Fisheries Society.

751 Mgaya YD. 1992. Density and production of Clinocottus globiceps and Oligocottus 752 maculosus(Cottidae) in tidepools at Helby Island, British Columbia. Marine ecology 753 progress series. Oldendorf 85:219-225.

754 Miller DJ., Lea RN. 1972. Guide to the coastal marine fishes of California. Sacramento: 755 California Department of Fish and Game.

756 Misitano DA. 1980. A Record of Internal Fertilization in the Roughback Sculpin Chitinotus 757 pugetensis with Descriptive Notes of Their Early Larvae. Copeia 1980:162-165.

758 Morris RW. 1952. Spawning behavior of the cottid fish Clinocottus recalvus (Greeley). Pacific $759 \quad$ Science 6:256-258.

760 Morris RW. 1956. Clasping Mechanism of the Cottid Fish Oligocottus snyderi Greeley. Pacific $761 \quad$ Science 10:314-317.

762 Munehara H. 1996. Sperm transfer during copulation in the marine sculpin Hemitripterus 763 764 villosus (Pisces: Scorpaeniformes) by means of a retractable genital duct and ovarian secretion in females. Copeia 1996:452-454.

765 Munehara H., Koya Y., Hayakawa Y., Takano K. 1997. Extracellular environments for the 766 initiation of external fertilization and micropylar plug formation in a cottid species, 

experimental marine biology and ecology 211:279-289.

769 Munehara H., Takano K., Koya Y. 1989. Internal gametic association and external fertilization in the elkhorn sculpin, Alcichthys alcicornis. Copeia:673-678.

771 Munehara H., Takano K., Koya Y. 1991. The little dragon sculpin Blepsias cirrhosus, another case of internal gametic association and external fertilization. Japanese Journal of Ichthyology 37:391-394.

\section{4}

Muñoz M. 2010. Reproduction in Scorpaeniformes. In: Cole KS ed. Reproduction and Sexuality 776 in Marine Fishes: Patterns and Processes. Berkley: University of California Press, 6589.

777 778

779

780

781

782

783

784

785

786

787

Nylander JA. 2004. MrModeltest. Program distributed by the author: Evolutionary Biology Centre, Uppsala University.

Oksanen J., Blanchet FG., Friendly M., Kindt R., Legendre P., McGlinn D., Minchin PR., O’Hara RB., Simpson GL., Solymos P., Stevens MHH., Szoecs E., Wagner H. 2017. vegan: Community Ecology Package.

Pagel M. 1994. Detecting correlated evolution on phylogenies: a general method for the comparative analysis of discrete characters. Proceedings of the Royal Society of London B: Biological Sciences 255:37-45.

Pagel M. 1999. Inferring the historical patterns of biological evolution. Nature 401:877-884.

Paradis E., Claude J., Strimmer K. 2004. APE: analyses of phylogenetics and evolution in R language. Bioinformatics 20:289-290. 
788 Petersen CW., Mazzoldi C., Zarrella KA., Hale RE. 2005. Fertilization mode, sperm

789

790

791

792

793

794

795

796

797

798

799

800

801

802

803

804

805

806

807

808

809

characteristics, mate choice and parental care patterns in Artedius spp.(Cottidae). Journal of fish biology 67:239-254.

Pinheiro J., Bates D., DebRoy S., Sarkar D., R Core Development Team. 2015. nlme: Linear and nonlinear mixed effects models. $R$ package version 3.2.2 <URL: http://CRAN.Rproject.org $/$ package $=$ nlme $>$.

Posada D., Buckley TR. 2004. Model selection and model averaging in phylogenetics: advantages of Akaike information criterion and Bayesian approaches over likelihood ratio tests. Systematic biology 53:793-808.

Potts GW. 1980. The littoral fishes of Little Cayman (West Indies). Atoll Research Bulletin $241: 43-52$.

Rambaut A., Suchard MA., Xie D., Drummond AJ. 2014. Tracer. Available from http://beast.bio.ed.ac.uk/Tracer.

Ramon ML., Knope ML. 2008. Molecular support for marine sculpin (Cottidae; Oligocottinae) diversification during the transition from the subtidal to intertidal habitat in the Northeastern Pacific Ocean. Molecular phylogenetics and evolution 46:475-483.

Revell LJ. 2012. phytools: an R package for phylogenetic comparative biology (and other things). Methods in Ecology and Evolution 3:217-223.

Rohlf FJ. 2007. tpsDig. Department of Ecology and Evolution, State University of New York at Stony Brook.

Rohlf FJ., Corti M. 2000. Use of two-block partial least-squares to study covariation in shape. Systematic Biology:740-753. 
810 Sabaj Pérez MH. 2009. Photographic atlas of fishes of the Guiana Shield. Bulletin of the $811 \quad$ Biological Society of Washington 17:52-59.

812 Sidlauskas B. 2008. Continuous and arrested morphological diversification in sister clades of 813 characiform fishes: a phylomorphospace approach. Evolution 62:3135-3156.

814 Smith WL., Busby MS. 2014. Phylogeny and taxonomy of sculpins, sandfishes, and snailfishes 815 (Perciformes: Cottoidei) with comments on the phylogenetic significance of their early816 life-history specializations. Molecular Phylogenetics and Evolution 79:332-352.

817 Strauss RE., Bookstein FL. 1982. The truss: body form reconstructions in morphometrics.

$818 \quad$ Systematic Biology 31:113-135.

819 Strauss RE., Fuiman LA. 1985. Quantitative comparisons of body form and allometry in larval 820 and adult Pacific sculpins (Teleostei: Cottidae). Canadian Journal of Zoology 63:1582-

821 1589.

822 Taranetz AY. 1941. On the classification and origin of the family Cottidae. University of British 823 Columbia Museum Contributions 5:1-28.

824 Thomson DA., Findley LT., Kerstitch AN. 2010. Reef fishes of the Sea of Cortez: The rocky825 shore fishes of the Gulf of California. University of Texas Press.

826 Thomson DA., Lehner CE. 1976. Resilience of a rocky intertidal fish community in a physically 827 unstable environment. Journal of Experimental Marine Biology and Ecology 22:1-29. 828 Yoshiyama RM. 1981. Distribution and abundance patterns of rocky intertidal fishes in central 829 California. Environmental Biology of Fishes 6:315-332.

830 Yoshiyama RM., Sassaman C., Lea RN. 1986. Rocky intertidal fish communities of California: 831 temporal and spatial variation. Environmental Biology of Fishes 17:23-40. 
832 Zander CD. 1972. Beziehungen zwischen Körperbau und Lebensweise bei Blenniidae (Pisces)

833 aus dem Roten Meer. I. Äuls sere Morphologie. Marine Biology 13:238-246.

834 


\section{Figure 1}

Histogram of all recorded collection depth from museum records of each species of the sculpin subfamily Oligocottinae and the outgroup taxon Chitonotus Pugetensis.

The $x$-axis represents bins of collection depth in meters. The first bin " 0 ," contains only collection depths that were recorded as 0 meters or where the habitat or collection depth is described as "tide pool," "intertidal," or the like. The median collection depth is indicated with a red arrow above the $x$-axis. The range of collection depths that contains $95 \%$ of all museum collection depth records is indicated with a black double-sided arrow below $\mathrm{x}$-axis. Where the $95 \%$ range extends beyond the $35 \mathrm{~m}$ depth bin, the arrow points to the right, indicating the "More" depth bin. All museum data analyzed herein are included in Supplementary Table 2. Precise values of minimum, maximum, 95\% depth ranges, mean, and sample size for the museum depth records of each species are given in Supplementary Table 4. 


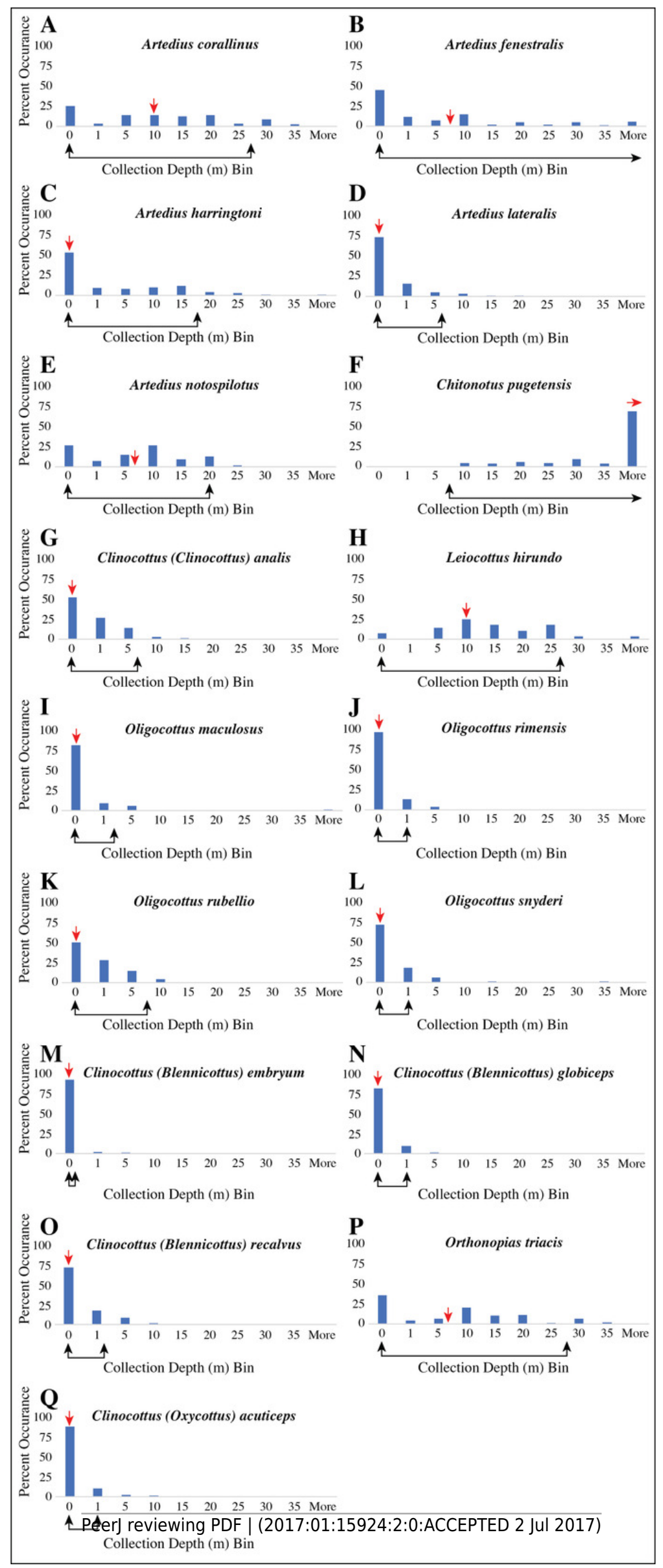




\section{Figure 2}

Lateral photograph of Clinocottus analis (OSIC 6710, 75.9mm SL) showing thirteen homologous landmarks used to capture overall body shape in oligocottine sculpins.

Landmark descriptions: 1) insertion of spinous dorsal fin, 2) insertion of soft dorsal fin, 3) insertion of anal fin, 4) ventral-most ray of the pectoral fin, 5) anterior-most tip of dentary 6) anterior-most tip of premaxilla 7) posterior-most tip of maxilla, 8) anteroventral-most point of orbit, 9) anteroventral-most point of orbit 10) anterodorsal-most point of orbit, 11) posteroventral-most point of orbit 10) anterodorsal-most point of orbit, 12) dorsal tip of dorsal-most preopercular spine, 13) insertion of epaxial musculature onto neurocranium.

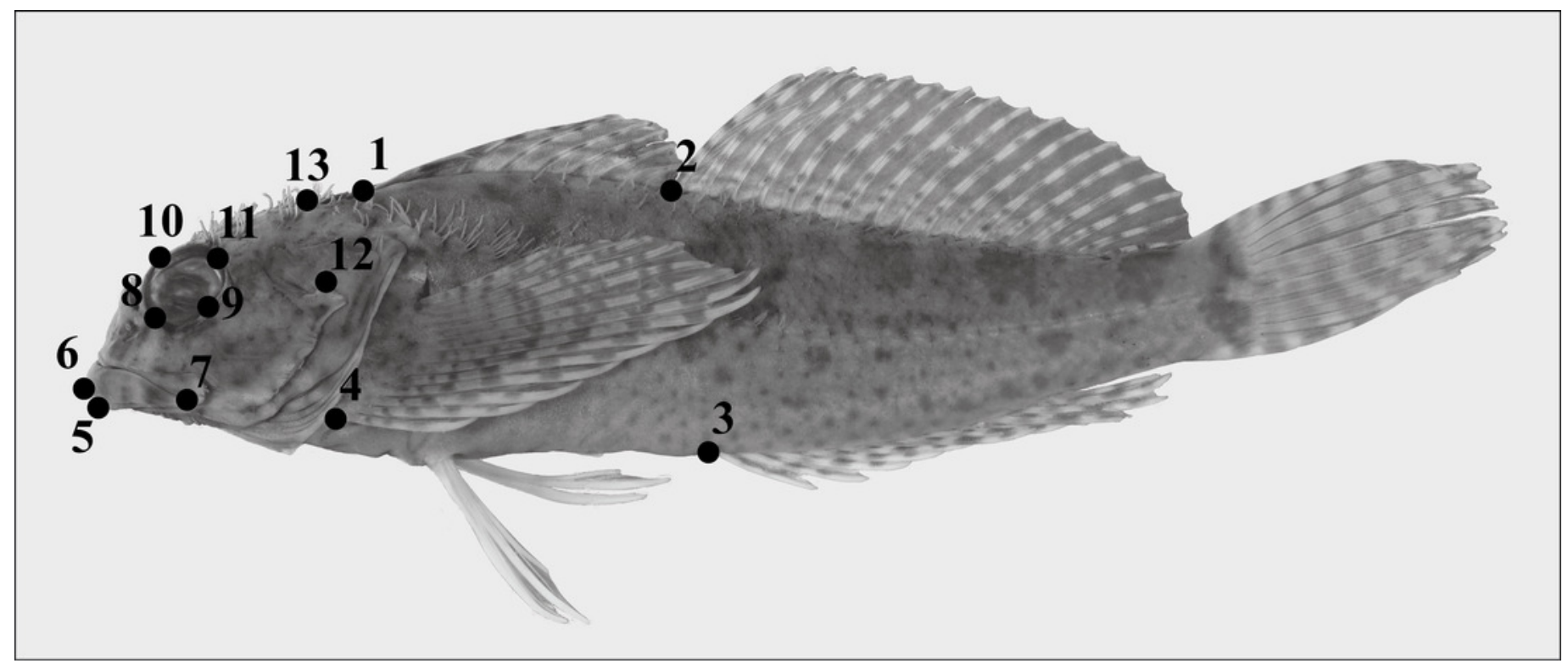




\section{Figure 3}

Phylogenetic hypothesis of the subfamily Oligocottinae.

Phylogeny is the maximum clade credibility tree from Bayesian phylogenetic inference conducted using four independent runs of 200 million generations each using the molecular dataset published in Buser and López (2015). Bayesian posterior probability scores are indicated at each node. Probabilities less than 0.50 are not displayed. The subfamily Oligocottinae, along with pertinent clades therein are labeled with arrows following the taxonomy suggested in Buser and López (2015).

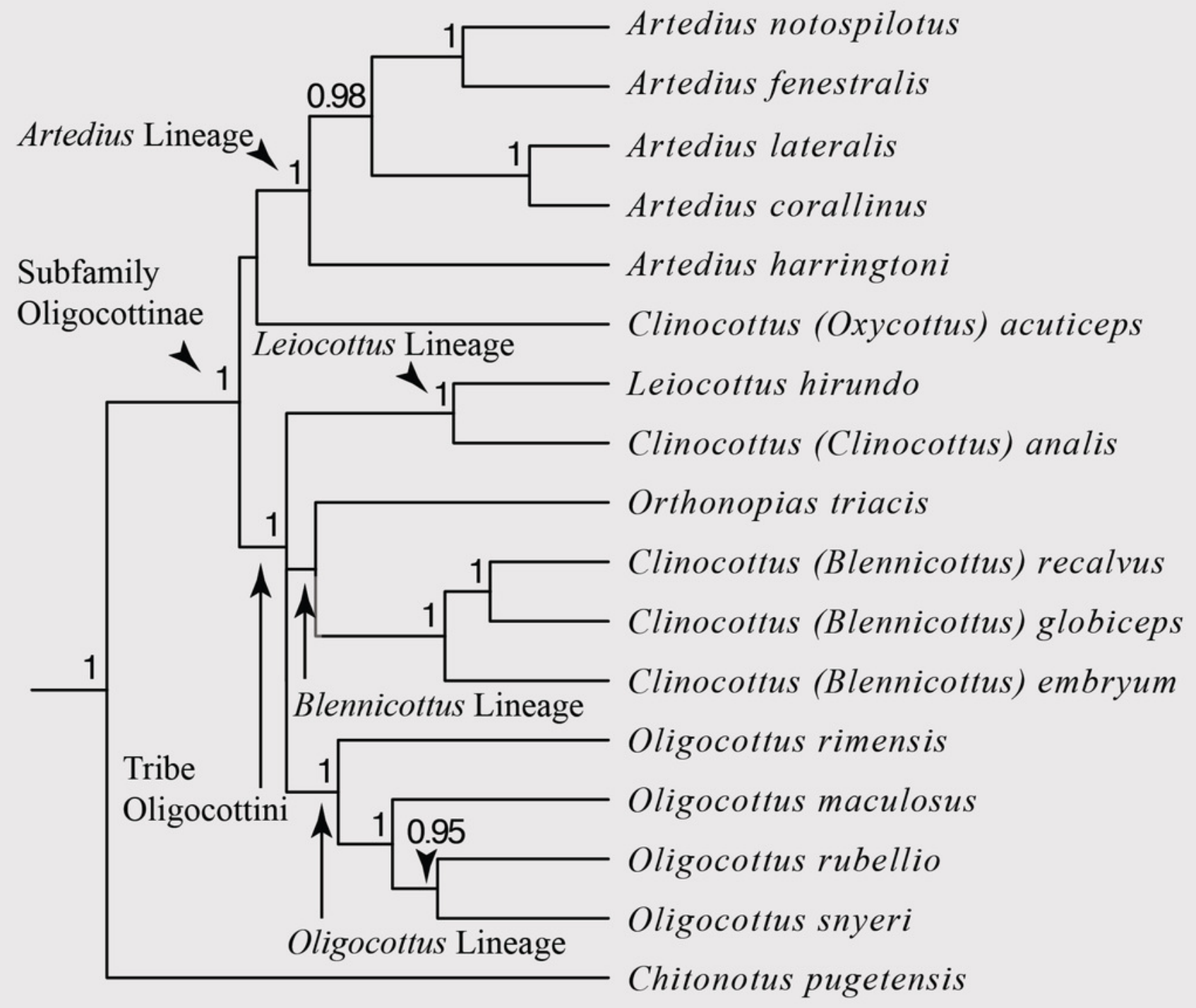




\section{Figure 4}

Inferred evolutionary history of maximum depth and maximum size of oligocottine species.

A phenogram showing the inferred evolutionary history of maximum depth is indicated on the left panel. Phylogenetic relationships are represented by white edges and bifurcation points represent inferred speciation events. Phylogenetic topology is from Bayesian MCC tree shown in Figure 3. Relative time is indicated on the horizontal axis and depth in meters indicated on the vertical axis. The tips and nodes of the phylogeny are positioned on the vertical axis to reflect the maximum depth or inferred maximum depth (respectively) of each taxon. Ancestral states for each node were inferred using maximum likelihood and 95\% confidence intervals for each state are represented with blue lines. Species names are abbreviated as follows: Artedius corallinus $=A r$. cor., $A$. fenestralis $=$ Ar. fen, $A$. harringtoni $=$ Ar. har., A. lateralis $=$ Ar. lat., $A$. notospilotus $=$ Ar. not., Chitonotus pugetensis $=$ Ch. pug., Clinocottus (Oxycottus) acuticeps $=\mathrm{Cl}$. acu., Clinocottus (Clinocottus) analis $=\mathrm{Cl}$. ana., Clinocottus (Blennicottus) embryum $=C l$. emb., C. (B.) globiceps $=C l$. glo., C. (B.) recalvus $=$ Cl. rec., Leiocottus hirundo $=$ Li. hir., Oligocottus maculosus $=$ Ol. mac., 0 . rimensis $=O \mathrm{O}$. rim., . rubellio $=$ Ol. rub., O. snyderi $=$ Ol. sny., Orthonopias triacis $=$ Or. tri. 


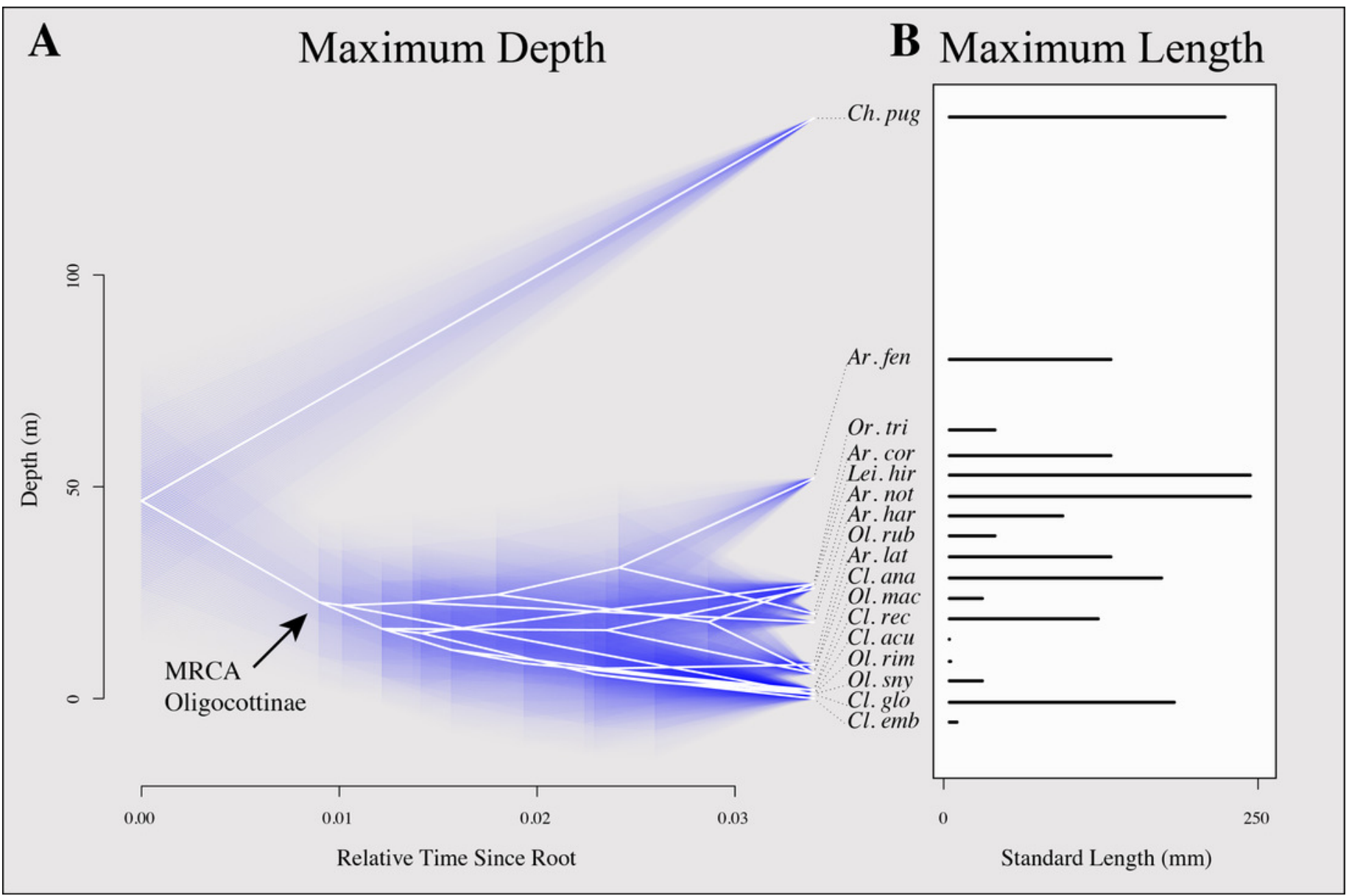




\section{Figure 5}

Bayesian MCC phylogeny of Oligocottinae with inferred evolutionary histories of the presence of an enlarged genital papilla and spermatozoon shape.

Where known, the presence of copulation in extant species is indicated by a " + " symbol following the abbreviated species name. Absence of copulation is indicated by a "-" symbol. Unknown states are indicated by the absence of a symbol. For the ancestral state reconstructions of the presence of an enlarged genital papilla and spermatozoon morphology, the proportional likelihood of each character for the ancestor of a given clade is depicted with a pie chart at each respective node. This scheme is also depicted on the branches between each node. Symbols at the tips of each phylogeny are indicative of the phylogenetic lineage of each species. Absence of a symbol at a tip indicates an unknown state. Squares represent the Artedius lineage, a triangle represents the lineage composed solely of the species Clinocottus (Oxycottus) acuticeps, hexagons represent the Leiocottus lineage, circles represent the Blennicottus lineage, stars represent the Oligocottus lineage, and a diamond represents a lineage composed solely of the species Chitonotus pugetensis. Species names are abbreviated as in Figure 4. 


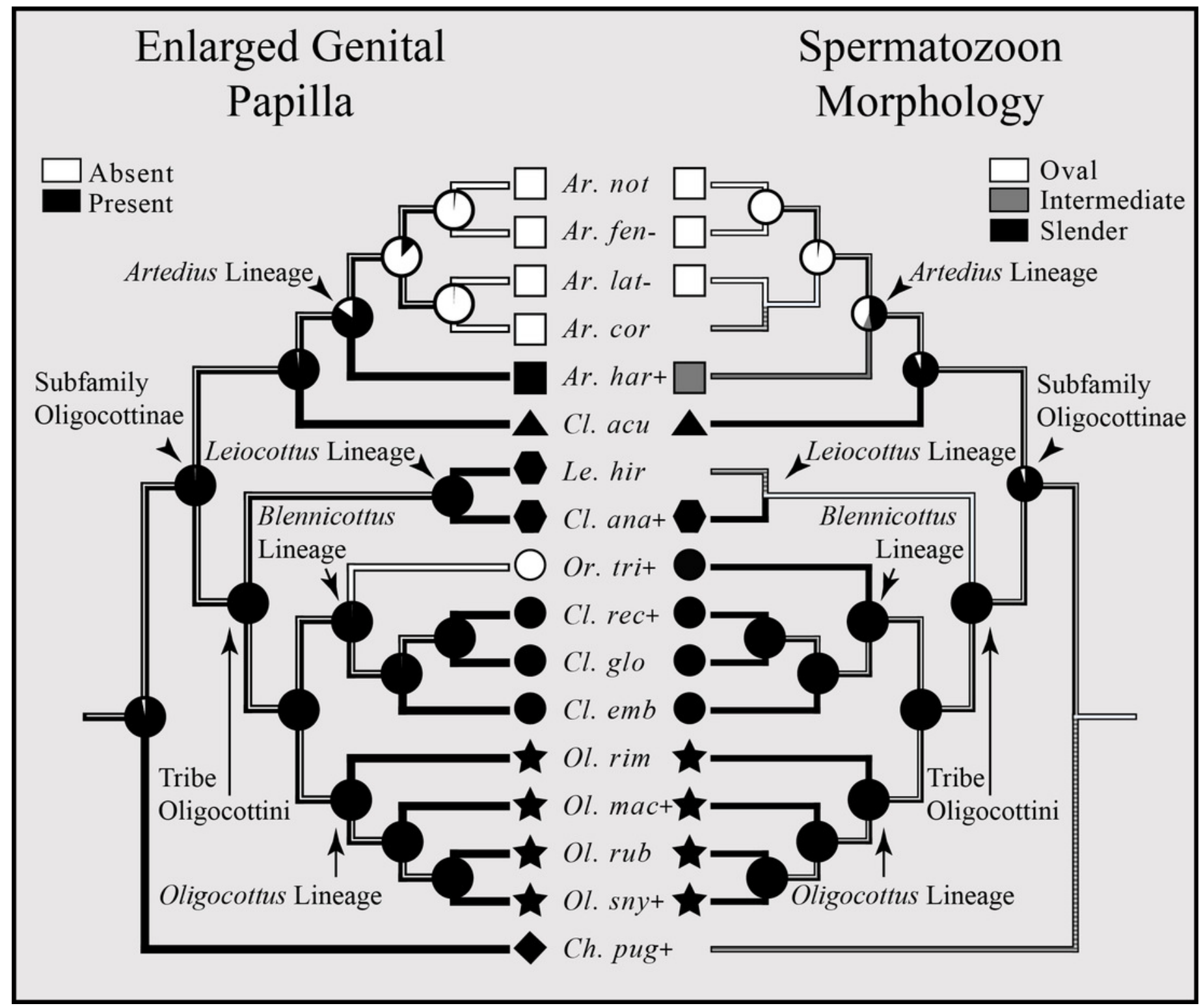




\section{Figure 6}

Bayesian MCC phylogeny of Oligocottinae with distribution and inferred evolutionary history of parental care.

The proportional likelihood of each character for the ancestor of a given clade is depicted with a pie chart at each respective node. Symbols at the tips of the phylogeny are indicative of the phylogenetic lineage of each species, as in Figure 4. Absence of a symbol or pie at a tip or node (respectively) indicates an unknown state. Species abbreviations in bold indicate a slender-type spermatozoon morphology present in that species. 


\section{Parental Care}

$\square$ Absent

Dresent

Subfamily

Oligocottinae

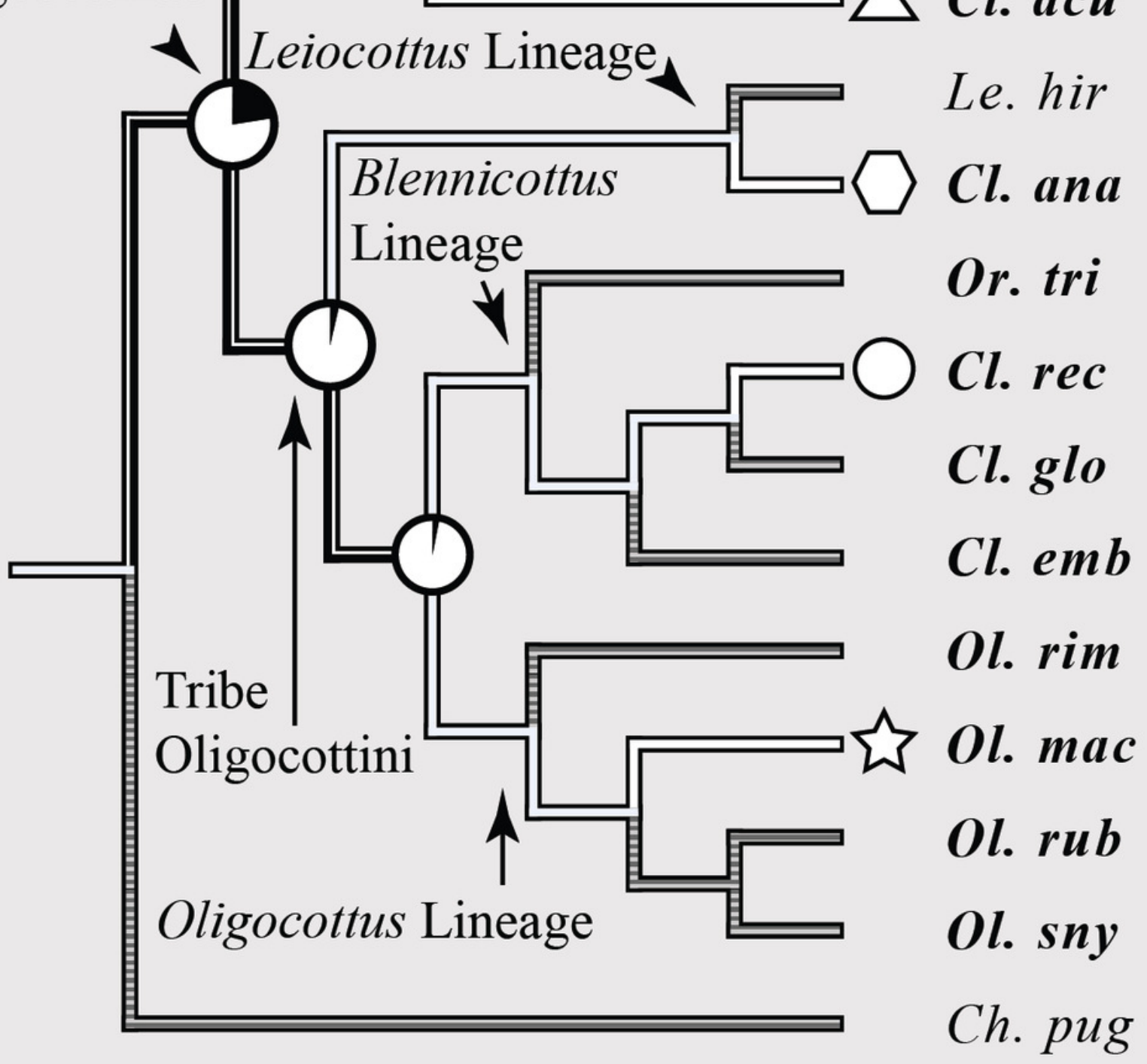




\section{Figure 7}

Body shape change in oligocottine sculpins represented by each of the two significant principal component axes.

Landmark locations are indicated by circles and are numbered as in Figure 1. Outline sketched from the lateral photograph of Clinocottus analis (OSIC 6710, 75.9mm SL) in Figure 2. Light blue and open circles shows displacement of landmarks and interpolated warping of the outline at a value of -1 on each PC axis. Dark blue and closed circles show displacement of landmarks and interpolated warping of the outline at a value of +1 on each PC axis.

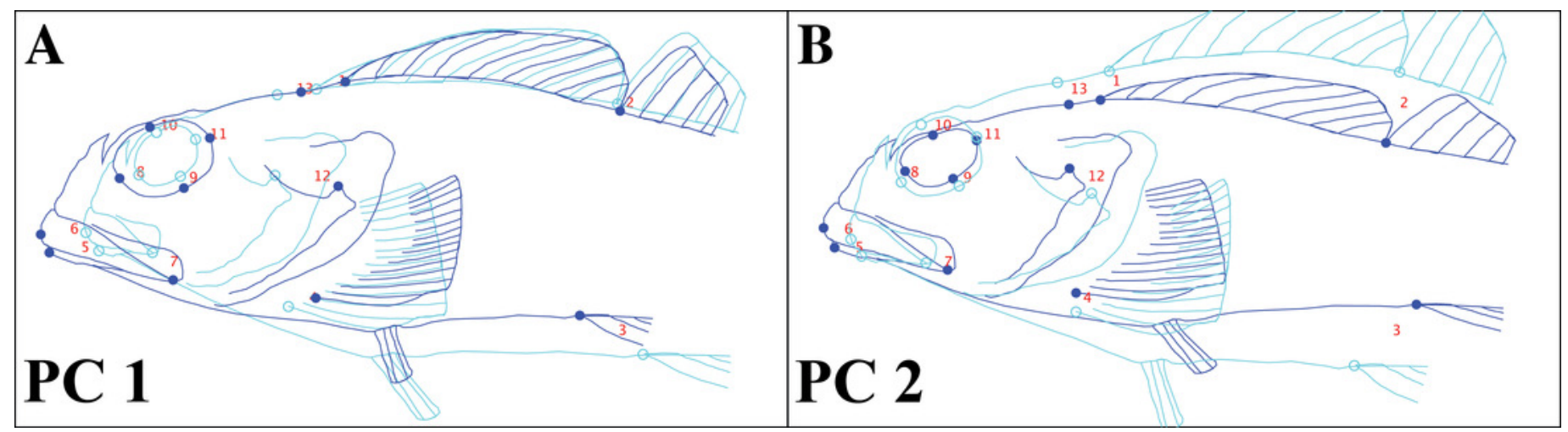


Figure 8

Phylomorphospace of the two significant principal components of body shape in the subfamily Oligocottinae.

Outlined symbols at the tips of each phylogeny are indicative of the phylogenetic lineage of each species as in Figure 5, ancestral nodes are indicated by small circles that are not outlined. Colors of each tip and internal node are indicative of the maximum depth of the species or the maximum likelihood (ML) estimate of the ancestral state of maximum depth, respectively. The shape change described by each PC axis is as shown as in Figure 5 . The depth data values are provided in Table 1.

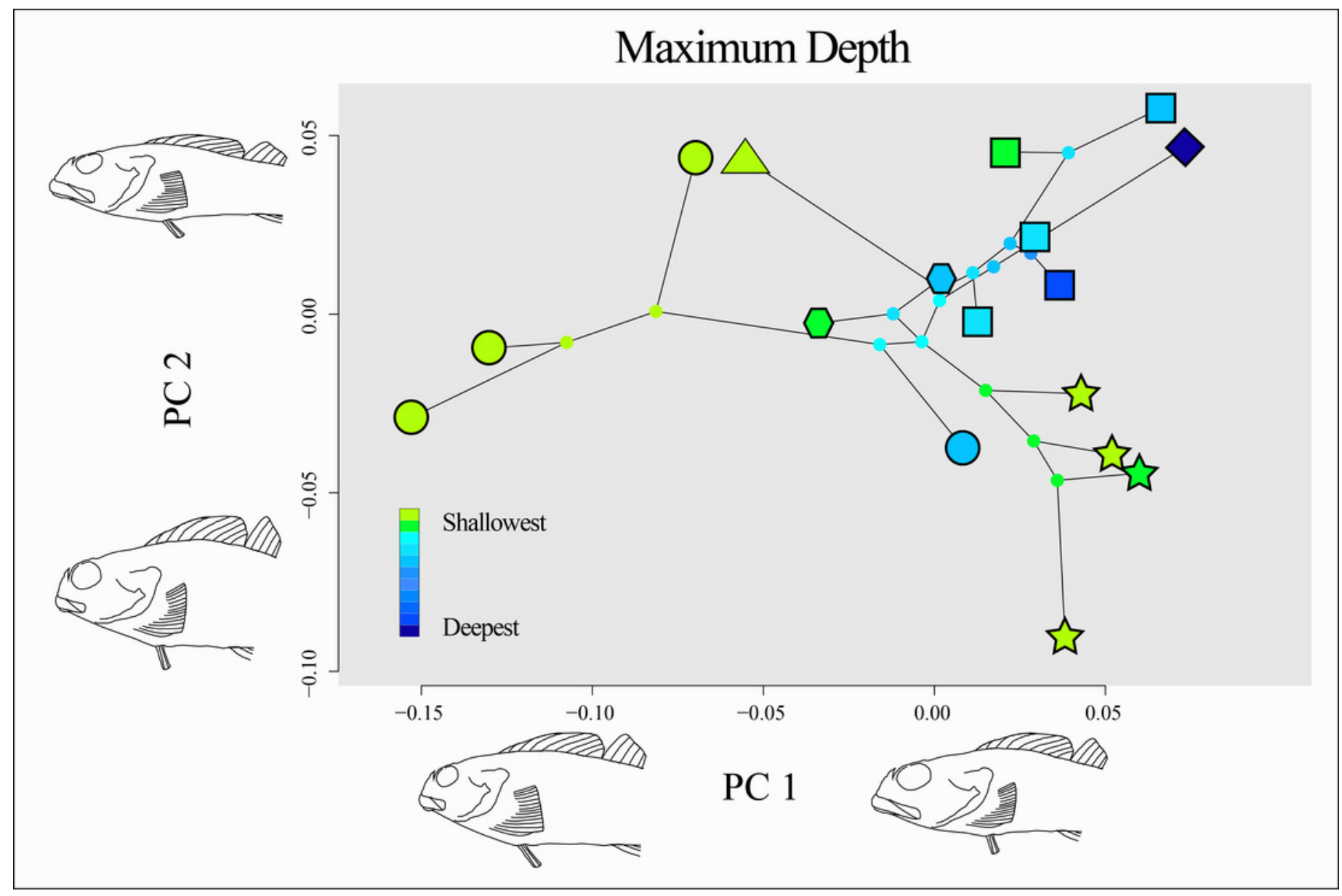




\section{Figure 9}

Body shape change associated with change in depth range.

Body shape is represented by the average shape variables (Procrustes-aligned landmark coordinates, illustrated in Figure 2) for each species. Depth range is represented by minimum and maximum collection depth from museum specimens of each species (see Table 1).

Partial least squares (PLS) axis 1 of body shape is indicated on the horizontal axis with body shape change described by the axis shown through a warped outline sketched from the lateral photograph of Clinocottus analis (OSIC 6710, 75.9mm SL) in Figure 2. The outline on the negative side of the axis shows body shape associated with a value of -1 on PLS axis 1, the outline on the positive side of the axis shows body shape associated with a value of +1 on PLS axis 1. The PLS axis 1 of depth range is indicated on the vertical axis. Symbols are indicative of the phylogenetic lineage of each species, as in Figure 5. 


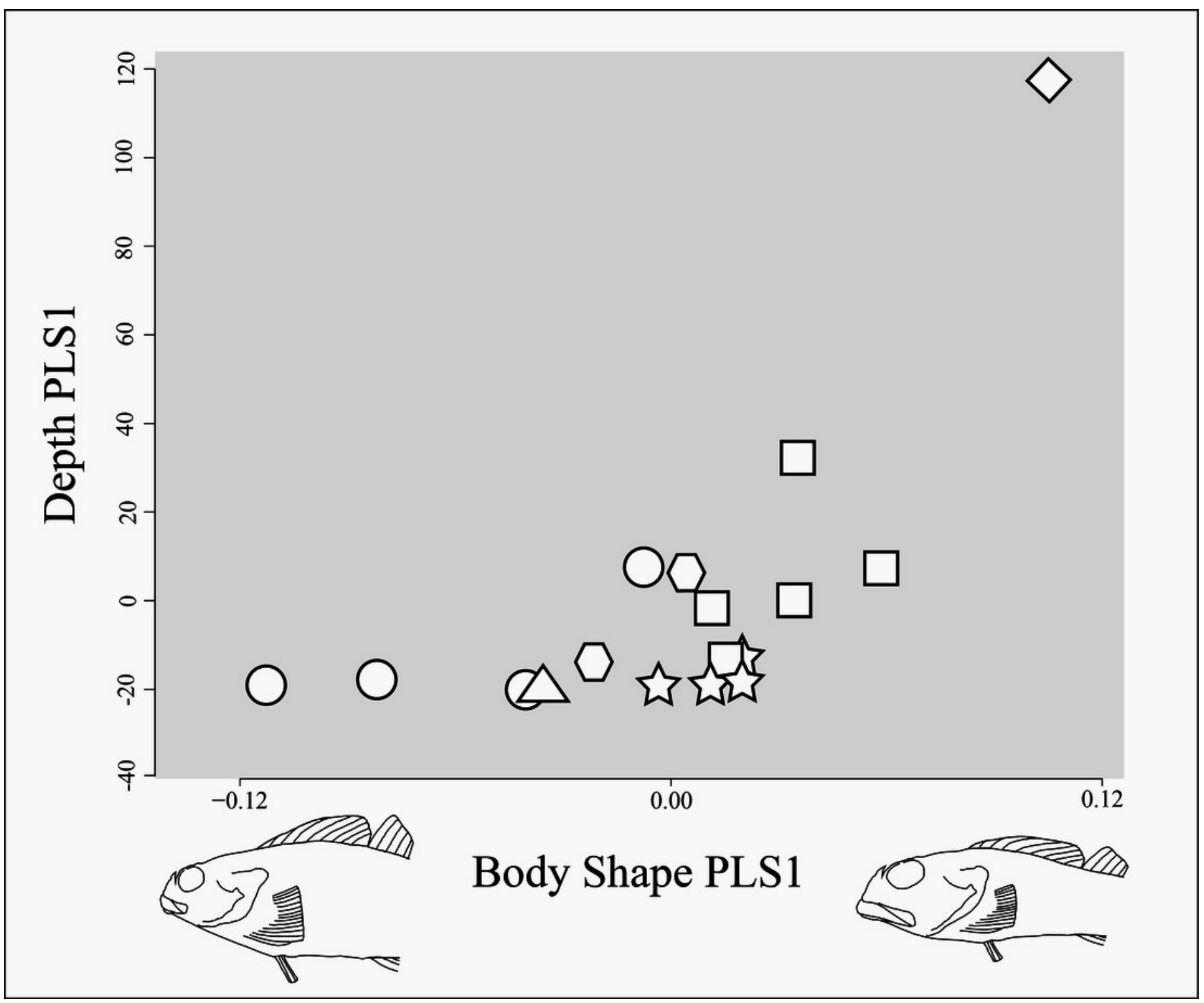




\section{Table $\mathbf{1}$ (on next page)}

Matrix of characters examined and character states for each species.

Numbered references for each state are indicated in superscript and are as follows: 1: Abe and Munehara (2009), 2: Bolin (1941), 3: Bolin (1944), 4: Hann (1930), 5: Hubbs (1966), 6 : Misitano (1980), 7: Morris (1952), 8: Morris (1956), 9: Petersen et al. (2005), 10: Mecklenburg et al. (2002), 11: Jackson (2003), 12: Miller and Lea (1972), 13: Eschmeyer et al. (1983), 14: Marliave (1981), 15: Koya et al. (2011). *Minimum and maximum depth are taken from the depth range that contains $95 \%$ of museum collection depths for each species. See Methods Supplementary Table 4. 


\begin{tabular}{|c|c|c|c|c|c|c|c|c|c|}
\hline Species & $\begin{array}{l}\text { Minimum } \\
\text { depth }(m)^{*}\end{array}$ & $\begin{array}{l}\text { Maximum } \\
\text { depth }(m)^{*}\end{array}$ & $\begin{array}{c}\text { Tide pool } \\
\text { occupancy }\end{array}$ & $\begin{array}{c}\text { Maximum } \\
\text { length }(\mathrm{mm})\end{array}$ & Squamation & $\begin{array}{c}\text { Enlarged } \\
\text { genital } \\
\text { papilla } \\
\end{array}$ & $\begin{array}{c}\text { Spermatozoon } \\
\text { morphology }\end{array}$ & Copulation & $\begin{array}{l}\text { Parental } \\
\text { care }\end{array}$ \\
\hline $\begin{array}{l}\text { Artedius } \\
\text { corallinus }\end{array}$ & 0 & 27 & Present & $140^{3,12,13}$ & Present $^{3}$ & Absent ${ }^{3}$ & $?$ & $?$ & $?$ \\
\hline $\begin{array}{l}\text { Artedius } \\
\text { fenestralis }\end{array}$ & 0 & 52 & Present & $140^{3,10,12,13}$ & Present $^{3}$ & Absent $^{3,10}$ & Oval $^{9}$ & Absent $^{9}$ & Present $^{9}$ \\
\hline $\begin{array}{l}\text { Artedius } \\
\text { harringtoni }\end{array}$ & 0 & 18 & Present & $102^{3,10,12,13}$ & Present $^{3}$ & Absent $^{3,10}$ & Intermediate $^{4,9}$ & Present $^{9}$ & Present $^{9}$ \\
\hline $\begin{array}{l}\text { Artedius } \\
\text { lateralis }\end{array}$ & 0 & 6 & Present & $140^{3,10,12,13}$ & Present ${ }^{3,11}$ & Absent $^{3,10}$ & Oval $1^{4,9,15}$ & Absent $^{9}$ & Present ${ }^{9}$ \\
\hline $\begin{array}{l}\text { Artedius } \\
\text { notospilotus }\end{array}$ & 0 & 20 & Present & $250^{3,12,13}$ & Present $^{3}$ & Absent $^{3}$ & Oval $^{4}$ & $?$ & $?$ \\
\hline $\begin{array}{l}\text { Chitonotus } \\
\text { pugetensis }\end{array}$ & 7 & 137 & Absent & $230^{3,10,12,13}$ & Present $t^{3,11}$ & Present $t^{3,10}$ & $?$ & Present $^{1,6}$ & $?$ \\
\hline $\begin{array}{l}\text { Clinocottus } \\
\text { (Oxycottus) } \\
\text { acuticeps }\end{array}$ & 0 & 1 & Present & $64^{3,10,12,13}$ & Absent $^{3}$ & Present $t^{3,10}$ & Slender ${ }^{4}$ & $?$ & Absent ${ }^{14}$ \\
\hline $\begin{array}{l}\text { Clinocottus } \\
\text { (Clinocottus) } \\
\text { analis }\end{array}$ & 0 & 6 & Present & $180^{3,12,13}$ & Present $^{3}$ & Present ${ }^{3}$ & Slender ${ }^{4}$ & Present ${ }^{1,5}$ & Absent ${ }^{1,5}$ \\
\hline $\begin{array}{l}\text { Clinocottus } \\
\text { (Blennicottus) } \\
\text { embryum }\end{array}$ & 0 & 0 & Present & $70^{3,10,12,13}$ & Absent $^{3}$ & Present ${ }^{3,10}$ & Slender ${ }^{4}$ & $?$ & $?$ \\
\hline $\begin{array}{l}\text { Clinocottus } \\
\text { (Blennicottus) } \\
\text { globiceps }\end{array}$ & 0 & 1 & Present & $190^{3,10,12,13}$ & Absent $^{3}$ & Present $t^{3,10}$ & Slender ${ }^{4}$ & $?$ & $?$ \\
\hline $\begin{array}{l}\text { Clinocottus } \\
\text { (Blennicottus) } \\
\text { recalvus }\end{array}$ & 0 & 2 & Present & $130^{3,12,13}$ & Absent $^{3}$ & Present $^{3}$ & Slender ${ }^{4}$ & Present $^{1,7}$ & Absent $^{1,7}$ \\
\hline $\begin{array}{l}\text { Leiocottus } \\
\text { hirundo }\end{array}$ & 0 & 26 & Absent & $250^{3,12,13}$ & Present $^{11}$ & Present ${ }^{3}$ & $?$ & $?$ & $?$ \\
\hline $\begin{array}{l}\text { Oligocottus } \\
\text { maculosus }\end{array}$ & 0 & 2 & Present & $90^{3,10,12,13}$ & Absent ${ }^{3,11}$ & Present ${ }^{3,10}$ & Slender 4,15 & Present $^{1}$ & Absent $^{1}$ \\
\hline $\begin{array}{l}\text { Oligocottus } \\
\text { rimensis }\end{array}$ & 0 & 1 & Present & $65^{3,10,12,13}$ & Present $^{3}$ & Present $^{3,10}$ & Slender ${ }^{4}$ & $?$ & $?$ \\
\hline
\end{tabular}




\begin{tabular}{|l|c|c|c|c|c|c|c|c|c|}
\hline $\begin{array}{l}\text { Oligocottus } \\
\text { rubellio }\end{array}$ & 0 & 8 & Present & $100^{3,12,13}$ & Absent $^{3}$ & Present $^{3}$ & Slender $^{4}$ & $?$ \\
\hline $\begin{array}{l}\text { Oligocottus } \\
\text { snyderi }\end{array}$ & 0 & 1 & Present & $90^{3,10,12,13}$ & Absent $^{3}$ & Present $^{3,10}$ & Slender $^{4,15}$ & Present $^{1,8}$ & $?$ \\
\hline $\begin{array}{l}\text { Orthonopias } \\
\text { triacis }\end{array}$ & 0 & 27 & Present & $100^{3,12,13}$ & Present $^{3,11}$ & Absent $^{3}$ & Slender $^{4,15}$ & Present $^{1,2}$ & $?$ \\
\hline
\end{tabular}




\section{Table 2 (on next page)}

Sample size ( $\mathrm{n}$ ) and museum lot number (Museum ID) of specimens examined for each species that was photographed for landmarking and body shape analysis.

Note: many museum lots contain multiple individuals. 


\begin{tabular}{|c|c|c|}
\hline Taxon & $\mathbf{n}$ & Museum ID \\
\hline Artedius corallinus & 8 & $\begin{array}{l}\text { OSIC 08140, SIO 457-34-55, SIO 057-34-55, } \\
\text { SIO H51-34-55C }\end{array}$ \\
\hline Artedius fenestralis & 9 & $\begin{array}{c}\text { OSIC 05879, OSIC 09206, UW } 000587 \text {, } \\
\text { UW 017420, UW } 118839\end{array}$ \\
\hline Artedius harringtoni & 15 & $\begin{array}{l}\text { OSIC 04533, OSIC 07471, OSIC } 11055 \text {, } \\
\text { UW 001011, UW } 027119 \text {, OSIC } 07474\end{array}$ \\
\hline Artedius lateralis & 10 & OSIC 03175, OSIC 03178 \\
\hline Artedius notospilotus & 2 & OSIC 02995, OSIC 07523 \\
\hline Chitonotus pugetensis & 4 & OSIC 05269, OSIC 07016 \\
\hline Clinocottus acuticeps & 7 & OSIC 06539, UAM 047689, UAM 047713 \\
\hline Clinocottus analis & 5 & OSIC 06707, OSIC 06710, OSIC 08136 \\
\hline Clinocottus embryum & 6 & OSIC 03009, OSIC 07071, UAM 47704 \\
\hline Clinocottus globiceps & 7 & OSIC 00272, OSIC 00275, OSIC 06600 \\
\hline Clinocottus recalvus & 5 & OSIC 08134 \\
\hline Leiocottus hirundo & 9 & OSIC 08132, SIO 059-307-55D, SIO 071-62-55 \\
\hline Oligocottus maculosus & 8 & OSIC 06628, OSIC 06663, OSIC 07467 \\
\hline Oligocottus rimensis & 6 & SIO 67-151 \\
\hline Oligocottus rubellio & 4 & OSIC 08133 \\
\hline Oligocottus snyderi & 4 & OSIC 06541, OSIC 06668 \\
\hline Orthonopias triacis & 6 & OSIC 08137 \\
\hline
\end{tabular}

